\title{
Winter warmings, tides and planetary waves: comparisions between CMAM (with interactive chemistry) and MFR-MetO observations and data
}

A. H. Manson ${ }^{1}$, C. Meek ${ }^{1}$, T. Chshyolkova ${ }^{1}$, C. McLandress ${ }^{2}$, S. K. Avery ${ }^{3}$, D. C. Fritts ${ }^{4}$, C. M. Hall ${ }^{5}$, W. K. Hocking ${ }^{6}$, K. Igarashi ${ }^{7}$, J. W. MacDougall ${ }^{6}$, Y. Murayama ${ }^{7}$, D. C. Riggin $^{4}$, D. Thorsen ${ }^{8}$, and R. A. Vincent ${ }^{9}$

${ }^{1}$ ISAS, University of Saskatchewan, Canada

${ }^{2}$ Department of Physics, University of Toronto, Canada

${ }^{3}$ University of Colorado, Boulder, CO, USA

${ }^{4}$ Colorado Research Associates, Boulder, CO, USA

${ }^{5}$ Auroral Observatory, University of Troms $\varnothing$, Troms $\varnothing$, Norway

${ }^{6}$ Department of Physics and Astronomy, University of Western Ontario, London, Canada

${ }^{7}$ National Institute of Information and Communications Technology, Tokyo, Japan

${ }^{8}$ Department of Electrical and Computer Engineering, University of Alaska, Fairbanks, USA

${ }^{9}$ Department of Physics, University of Adelaide, Australia

Received: 17 January 2006 - Revised: 16 August 2006 - Accepted: 24 August 2006 - Published: 20 October 2006

\begin{abstract}
Following earlier comparisons using the Canadian Middle Atmosphere Model (CMAM, without interactive chemistry), the dynamical characteristics of the model are assessed with interactive chemistry activated. Timesequences of temperatures and winds at Troms $\varnothing\left(70^{\circ} \mathrm{N}\right)$ show that the model has more frequent and earlier stratospheric winter warmings than typically observed. Wavelets at mesospheric heights $(76,85 \mathrm{~km})$ and from equator to polar regions show that CMAM tides are generally larger, but planetary waves (PW) smaller, than medium frequency (MF) radar-derived values.

Tides modelled for eight geographic locations during the four seasons are not strikingly different from the earlier CMAM experiment; although monthly data now allow these detailed seasonal variations (local combinations of migrating and non-migrating components) within the mesosphere (circa $50-80 \mathrm{~km}$ ) to be demonstrated for the first time. The dominant semi-diurnal tide of middle latitudes is, as in the earlier papers, quite well realized in CMAM. Regarding the diurnal tide, it is shown here and in an earlier study by one of the authors, that the main characteristics of the diurnal tide at low latitudes (where the $\mathrm{S}(1,1)$ mode dominates) are well captured by the model. However, in this experiment there are some other unobserved features for the diurnal tide, which are quite similar to those noted in the earlier CMAM experiment: low latitude amplitudes are larger than observed
\end{abstract}

Correspondence to: A. H. Manson

(alan.manson@usask.ca) at $82 \mathrm{~km}$, and middle latitudes feature an unobserved low altitude $(73 \mathrm{~km})$ summer maximum. Phases, especially at low and middle $\left(\operatorname{circa} 42^{\circ} \mathrm{N}\right)$ latitudes, do not match observations well.

Mesospheric seasonal tidal variations available from the CUJO (Canada U.S. Japan Opportunity) radar (MFR) network (sites $40-45^{\circ} \mathrm{N}$ ) reveal interesting longitudinal differences between the CMAM and the MFR observations. In addition, model and observations differ in the character of the vertical phase variations at each network-location.

Finally, the seasonal variations of planetary wave (PW) activity available from CMAM and the MFR show quite good agreement, apart from the amplitude differences (smaller in CMAM above $70 \mathrm{~km}$ ). A major difference for the 16-d PW is that CMAM shows large amplitudes before the winter solstice; and for the 2-d PW, while both CMAM and MFR show summer and winter activity, the observed summer mesopause and winter mesospheric wave activities are stronger and more extended in height.

Models such as CMAM, operated without dataassimilation, are now able to provide increasingly realistic climatologies of middle atmosphere tides and PW activity. Differences do exist however, and so discussion of the various factors affecting tidal and PW characteristics in atmospheres, modelled and observed, is provided. Other diagnostics of model-characteristics and of future desirable model experiments are suggested.

Published by Copernicus GmbH on behalf of the European Geosciences Union. 


\section{Introduction}

In our earlier papers (Manson et al., 2002a, b; Papers 1 \& 2), which used CMAM model data from an experiment carried out without interactive chemistry, the emphasis was upon gravity wave (GW) effects, and tides (observed and modelled) during the months of January, April, July and October.

The parameterized GW drag included that due to topography (McFarlane, 1987), and the effects of non-orographically excited waves were due to two different schemes (Medvedev and Klaassen, 1995; Hines, 1997a, b). The ozone distribution in CMAM at that time was consistent with the COSPAR International Reference Atmosphere (CIRA, Keating et al., 1990) and the latent heat release from deep convection was due to the parameterization of Zhang and McFarlane (1995).

Very briefly, the comparisons of GW spectra in Paper 1 showed, for the first time, the differences in spectral intensity between the resolved GW in CMAM and the observed GW from the MF radars at mesospheric heights $(72-78 \mathrm{~km})$. For periods less than $2 \mathrm{~h}$ the differences were substantial (several orders of magnitude), due to both limited time and space sampling (20 min and $400 \mathrm{~km}$ grid spacing). It is not possible to infer, in spectral format, the contribution of $\mathrm{GW}$ from the non-resolved parameterized GW. The parameterization due to Medvedev and Klaassen produced more realistic zonal winds (EW), as shown in latitudinal contour plots for the mesosphere $(60-87 \mathrm{~km})$. Regarding the tides, as shown in Papers 1 and 2, the CMAM 12-h (semi-diurnal, SD) tide was quite similar to observations: amplitudes and phases were both often similar, with "Medvedev and Klaassen" tides being more regular than the "Hines-parameterized" results. For the 24-h (diurnal, D) tide agreements were less satisfactory: modeled amplitudes at lower latitudes $(\leq 35 \mathrm{~N})$ and near $80 \mathrm{~km}$ were larger than observed in equinoxes; summer mid-latitude values were anomalously large for both parameterizations; and although phases at low latitudes were quite similar for CMAM and MFR data, at middle latitudes significant differences occurred for both GW parameterizations. Indeed for this tide the specific tidal models of GSWM (1995 and 2000 versions of the "Global Scale Wave Model") were better regarding phase variations with season (1 month samples), altitude and latitude. The amplitudes, which in the 2000 version were effectively normalized to satellite observations (UARS-HRDI), were also closer to the radar observations near $80 \mathrm{~km}$.

A new series of experiments using the CMAM with interactive chemistry (de Grandpré et al., 2000, 1997) provided an opportunity to further assess the model's capability in producing realistic tidal and PW fields. It is to be expected that the modifications in ozone distributions, now consistent with the dynamics and radiation, will modify the modelled tides in the mesosphere. The differences in model characteristics are described later in Sect. 2. For the experiment described here, 21 years of continuous model data were provided, which allowed us to assess the seasonal variations of the waves within the mesosphere with 10-day resolution. This allowed demonstration of the seasonal tidal evolutions (amplitudes and phases; $55-88 \mathrm{~km}$ ) at eight specific locations (these are then combinations of migrating and non-migrating components) for the first time, the assessment of inter-annual variability, and also consideration of longitudinal variability over the locations of the CUJO (Canada U.S. Japan Opportunity) MFR network. The latter has allowed consideration of the effects of migrating and non-migrating components. The seasonal mesospheric tidal evolutions shown by McLandress (2002a) are for the migrating components only, due to averaging of satellite data (UARS-WINDII: Upper Atmosphere Research Satellite-Wind Imaging Interferometer) over all longitudes. It is important to reiterate that the tides discussed here are for radar observations at particular geographic locations, and the CMAM tides are also for those same latitudes-longitudes. As such, the tides shown here include both migrating and non-migrating components.

In Sect. 2 the characteristics of the radars and the CMAM are provided, along with description of the common analysis methods applied to both data sets. In Sect. 3, timesequences for a high latitude location $(70 \mathrm{~N}$, Troms $\varnothing)$ from CMAM, MFR and MetO data (UK Meteorological Office, data-assimilation products) are compared, to assess the stratospheric winter warmings and their characteristics. Section 4 provides spectral wavelets (6-h to $30-d$ ) for CMAM and MFR data and follows that with high resolution variance spectra of CMAM and MFR to investigate the spectral nature of the tidal signals. The seasonal variations and climatologies of tides (12-, 24-h) and planetary waves, along with indications of latitudinal, inter-annual and longitudinal variabilities are given in Sects. 5 and 6, respectively. We conclude in Sect. 7.

\section{Description of radars, CMAM, MetO, and data anal- ysis}

\subsection{MF radars}

These systems have been described in Paper 1 and 2, so the comments here are relatively brief. The basic analysis applied to the complex radar signals is the full correlation analysis (FCA) for spaced antenna systems. The variant developed by Meek (1980) is used for several stations (Troms $\emptyset$ 70 N, 19 E, Saskatoon 52 N, 107 W, London 43 N, 81 W, Platteville $40 \mathrm{~N}, 105 \mathrm{~W}$ ), partly due to its usefulness in dealing with correlograms that are noisier; while the classical method due to Professor Basil Briggs (Adelaide) e.g. Isler and Fritts, 1996), is used at the other stations (Yamagawa $31 \mathrm{~N}, 131 \mathrm{E}$, Wakkanai $45 \mathrm{~N}, 142 \mathrm{E}$, Hawaii $22 \mathrm{~N}, 159 \mathrm{~W}$ and Christmas Island $2 \mathrm{~N}, 157 \mathrm{~W}$ ). Comparisons have shown no significant differences between these methods. The radars provide samples of wind every 2 or $3 \mathrm{~km}$ (circa $70-100 \mathrm{~km}$ ) and 2 or $5 \mathrm{~min}$ on a continuous basis. Some loss of data occurs if the 
ionospheric scatterers are weak or less numerous, and if the criteria for the FCA are not met. In this paper, the years of 2001 and 2002 were selected as the best years for the MFR data, given the comparative newness of several radars (data from 1994 were retained for the equatorial location, due to their superior quality).

Generally, and based upon data from Platteville, Saskatoon and Troms $\varnothing$ (middle to high latitudes), the observed inter-annual variations of the seasonal positions of tidal maxima, and of vertical phase structure, are modest (especially evident in the seasonal (12-month) height-versus-time contour plots (Sect. 2.4)). However at lower latitudes interannual variations of amplitude for the diurnal tide are large near the March equinoctial-maxima and discussions will be appropriately included in later sections (5.2 and 5.4) (Vincent et al., 1998; Manson et al., 2002b). The only radar new to the CMAM studies is Platteville, and it along with Saskatoon, London, Wakkanai and Yamagawa comprise the new CUJO network.

Since model-radar wind and tide comparisons are made later, some comment upon the accuracy of the radar-winds is appropriate. Examples of system-comparisons including MFR, Meteor Wind Radars (MWR), Fabry-Perot Interferometers, UARS-HRDI (Upper Atmosphere Research Satellite-High Resolution Doppler Interferometer), rockets and radars, have been extensive over the last 10 years e.g. Manson et al. (1996), Meek et al. (1996) and Paper 1. In all of these studies the phases of the tides, or directions of the winds, have generally been satisfactorily consistent (e.g. means within standard errors), as assessed by the authors. Most recently we have exhaustively compared MFR and MWR winds data from systems at Troms $\varnothing(70 \mathrm{~N}, 19 \mathrm{E})$ and Esrange (68 N, 21 E) separated by $200 \mathrm{~km}$ (Manson et al., 2004a). The MWR/MFR annual mean ratios were 1.1 at $82 \mathrm{~km}$ and 1.1 (summer) to 1.3 (winter) at $85 \mathrm{~km}$. (The larger winter values are thought to be due to a seasonal variation in radar scattering statistics.) The latter is the maximum height used comparatively, in this study. However the mean ratio was 1.6 at $97 \mathrm{~km}$ (similar to the HRDI/MFR ratio of Meek et al., 1997), and some mention of that will be made when the MFR amplitudes at the maximum height in the plots are discussed.

There is one last comment to be made. Studies made over recent years (e.g. Papers 1 and 2; Manson et al., 2004c) have shown a tendency for the London wind amplitudes to be somewhat smaller than those at nearby latitudes. Assessment of the analysis method used at London, has indicated differences in the algorithm used for the correlograms within the FCA; preliminary wind speed comparisons using two independent analysis systems operating on the same raw radar data sequences, one similar to that used at Saskatoon, has revealed a small-bias for London values of 1.2. This correction factor has been applied to some figures in the study (Figs. 2, $4,9,11$ and 12).

\subsection{CMAM}

The CMAM is a 3-D spectral general circulation model (GCM) extending from the ground to a height of approximately $100 \mathrm{~km}$. The prognostic fields are expanded in a series of spherical harmonic functions with triangular truncation at total wave number $n=32$ (T32) corresponding to a horizontal grid spacing of about $600 \mathrm{~km}$ at middle latitudes. The model contains 65 levels in the vertical, with a resolution of approximately 2 to $2.5 \mathrm{~km}$ above the tropopause. Realistic surface topography, planetary boundary-layer effects, parameterizations of shallow and deep convection, and comprehensive shortwave (solar) and longwave (terrestrial) radiation schemes are all included in the model. The reader is referred to Beagley et al. (1997) for further details.

The finite resolution of CMAM and other GCMs makes it impossible to explicitly represent the effects of GWs with spatial scales smaller than the model grid spacing. (Note that resolved GWs, with scales larger than the model grid spacing, are routinely excited in the model by a variety of sources including shear instabilities and flow over topography). In order to represent the effects of unresolved (sub grid-scale) GWs on the resolved flow within CMAM and other GCMs, GW drag parameterization schemes are employed. The parameterization of drag due to the breaking of waves excited by sub grid-scale topography is described in McFarlane (1987); this scheme is included in the simulation presented here. The effects of GW that are generated from unresolved non-orographic sources such as moist convection and shear instabilities are represented in this study using the parameterization of Hines (1997b); and its implementation in the CMAM is described in McLandress (1998). A simple Rayleigh-drag "sponge" layer is also employed for the non-zonal part of the horizontal wind field above the $0.01 \mathrm{mb}$ level $(\sim 80 \mathrm{~km})$ in order to prevent the reflection of upward propagating waves at the model upper boundary.

For this CMAM experiment, a comprehensive chemistry package interactively coupled with the radiative and dynamical modules has been used (de Grandpré et al., 2000). The chemistry module contains 44 species including necessary oxygen, hydrogen, nitrogen, chlorine, bromine and methane oxidation cycle species. Photochemical balance equations are solved throughout the middle atmosphere at every dynamical time step. A full diurnal cycle is simulated, with photolysis rates provided by a "look-up" table. This approach provides a complete and comprehensive representation of transport, emission, and photochemistry of various constituents from the surface to the mesopause region. A detailed comparison of model results with observations (CIRA of 1990) indicated (de Grandpre et al., 2000) that the ozone distribution and variability are in good agreement with observations throughout most of the model domain; in the upper stratosphere the model underestimates the ozone. The vertical ozone distribution is generally well represented by the model up to the mesopause region. Comparisons with 
measurements showed that the phase and amplitude of the seasonal variation as well as shorter timescale variations are well represented by CMAM at various latitudes and heights. It was found that the incorporation of ozone radiative feedback results in a cooling of $\sim 8 \mathrm{~K}$ in the summer stratopause region, which corrects a warm bias that results when climatological ozone is used. Realistic ozone concentrations are very important for this present study, as its horizontal and altitudinal distributions are crucial for effective forcing of both semi-diurnal and diurnal solar tides (e.g. Hagan, 1996). We note in conclusion that the present CMAM experiment used the Hines' parameterization rather than the MedvedevKlaassen used by de Grandpré et al. (2000). It is considered by the authors of the last named paper (private communication) that this is not a significant change and that realistic ozone distributions will be represented within the model data shown here.

CMAM output values have been made available for the locations of the MF radars, with continuous time sequences (10 min samples) over 21 years. Data have been archived at 15 geopotential heights between 55 and $88 \mathrm{~km}$, with a nominal vertical resolution of $3 \mathrm{~km}$.

\subsection{MetO}

We have also used stratospheric fields of daily (at 12:00 UTC, Coordinate Universal Time) temperature and wind components provided by the UK Meteorological Office (MetO) from the British Atmospheric Data Center (BADC) website at http://badc.nerc.ac.uk. These data have global coverage with $2.5^{\circ}$ latitudinal and $3.75^{\circ}$ longitudinal steps and are available for 22 pressure levels from 1000 mbar to $0.316 \mathrm{mbar}(\sim 0-55 \mathrm{~km})$. The description of the original data assimilation system is in Swinbank and O'Neill (1994a) and of the new (November 2000) three-dimensional variational (3D-VAR) system in Swinbank and Ortland (2003); basically, data (now including radiances) are continually incorporated in a global circulation model, and updated atmospheric samples of temperatures, winds and pressure are made available with daily temporal resolution. Systematic errors in the model are reported to be small except near the upper boundary where they are attributed to shortcomings in the parameterizations of gravity-wave drag and radiation. The MetO analyses well represent the major features of atmospheric circulation. For example, the global fields include quasibiennial and semi-annual oscillations at low latitudes (Swinbank and O'Neill, 1994b), and the quasi 2-day wave and an inertial circulation (Orsolini et al., 1997).

\subsection{Analysis}

The analyses used in Papers 1, 2 and in Manson et al. (2003) are also used here, and are applied to both the MFR and CMAM data. The CMAM data are ideal in that there are no gaps, while the MFR data will always have gaps, and there are criteria which are applied to ensure that all analyses are robust.

To provide seasonal (12-month) plots of atmospheric oscillations from $5 \mathrm{~h}$ to 30 days at a chosen height a wavelet analysis is applied to appropriate years of hourly mean winds with additional data at the ends, if available, to cover the full sliding window for all wave periods used (Fig. 2). A Gaussian window of length 6 times the period (truncated at 0.05 of peak value) is used to approximate a Morlet wavelet analysis (Kumar and Foufoula-Georgiou, 1997), but one in which gaps do not have to be filled. A Fourier transform (not an FFT) is therefore used and applied to existing data points only. Each time-axis pixel (800 are used) represents several hours, since the axis covers 1 year. Breaks in the heavy dataexistence line at the bottom of the frame indicates that there were no data for those hours, and are a warning that spectral data near the edges of, and during, these intervals may be inaccurate. The period scale uses 600 pixels and is linear in the logarithm of the period from 5 to $730 \mathrm{~h}$. Each pixel represents one spectral value, and there is no smoothing. Amplitudes are corrected after calculations for attenuation by the window, but on the assumption that there were no significant gaps. In the plot the value in $\mathrm{dB}$ is equal to $20 \log _{10}$ (wave amplitude in $\mathrm{m} / \mathrm{s}$ ), since this provides a better colourcoverage of the wide range of values.

The spectral analysis method used (Fig. 3) on the horizontal winds is the classical periodogram method, but for a non-linear set of frequencies. The purpose is to expand the low frequency portion of the plots.

A common analysis has been used to obtain the amplitudes and phases of the monthly diurnal and semi-diurnal oscillations in the wind field. First, sequences of hourly means were formed. Then for each month of chosen-years for the CMAM data an harmonic analysis was applied to the 2831 day time-sequences of hourly values (zonal, E-W; meridional, N-S), for the 12- and 24-h oscillations. Contour plots of tidal phases and amplitudes, for heights $(55-88 \mathrm{~km})$ versus latitude of the CMAM data, are provided in Fig. 4. Such plots for the MFR data were also shown in Manson et al. (2002a), but the limited data for some locations made these diagrams of only modest value. Here we will simply refer the reader to the height versus time plots for the tides which are derived from the MFR data.

To produce the plots of the tides, for heights versus days of the year, harmonic analysis was applied to 2 day sets of data (55-88 km for CMAM; 61-97 km for the MFR) for individual model and observed years (Figs. 5-10). These data were then vector-averaged into 10 day bins, and smoothing was applied to the phases. The contouring procedure employs a bilinear patch method, viz. the interpolated value is $a x+b y+c x y+d$, where $a, b, c$, and d are solved from the corner values of a cell. Any pixels representing a value greater than the maximum in the legend are set equal to the maximum. In the case of phase contours, two separate bilinear patch calculations are done, one for cosine and one for sine. 
The resulting pair of interpolated values at each point in the cell is recombined to get its phase value. If the phases at corners of the cell have a spread greater than 180 degrees, then no interpolation is attempted since the possibility of multiple solutions cannot be ignored, and the cell is left un-filled.

Finally, an independent planetary wave (PW) analysis is done for selected frequencies, starting with a year of hourly mean data which is extended at the ends, if data are available, to accommodate the desired window length. (It is noted here that for individual radars and a limited number of locations, the PW are recognized by dominant periodicities rather than the equally valuable horizontal wave-numbers.) For the 16day period (bandwidth 13-19 days, Luo et al., 2000) a 48day window length, and for 2-day periods (band-width 1.5-3 days) a 24-day window, are each shifted in 5-day steps over the year (Figs. 11-12). For each of these window-lengths the appropriate mean (48-, 24-day) is removed and used to represent the background wind, a full cosine window (Hanning) is applied, and the Fourier transform is done at the appropriate range of PW frequencies. Gaps are not filled.

\section{Stratospheric time sequences (CMAM and MetO) for the Tromsø location $(70 \mathrm{~N})$ and choice of data inter- vals}

The temporal characteristics of the winds and temperatures at a high latitude station such as Troms $\emptyset(70 \mathrm{~N})$, during the winter months, are of great significance dynamically. The drag exerted by breaking planetary waves is responsible for the Brewer-Dobson circulation, with its inherent poleward flow. Enhancements in this circulation lead to "stronger down-welling over the pole, therefore warmer polar temperatures, and a weaker polar vortex" (Shepherd, 2000). The polar vortex is subject to disturbances (the so-called minor warmings) and breakdowns, as revealed most dramatically in Sudden Stratospheric Warmings (SSW) (Chshyolkova et al., 2006; Manson et al., 2002d; Liu and Roble, 2002; Shepherd, 2000). Further, given the effects of the PW and polar vortex structure (during SSW) upon hemispheric (especially middle to high latitudes) ozone distributions (Randel, 1993; Baldwin et al., 2003) and also upon the temperatures and winds, and the propagation of various modes into the middle atmosphere, tidal characteristics (especially for the 12-h tide) may be expected to be affected for several months of any winter which is experiencing breakdowns during the mid-winter or spring. For example, tidal profiles measured during a SSW changed significantly compared to those for undisturbed intervals (Manson et al., 1984).

An earlier study of the variability of the Arctic Polar Vortex within CMAM (without interactive chemistry) by Chaffey and Fyfe (2001), revealed strong dependence upon the presence of GW parameterization (non-orographic). However, even with its inclusions, the $\mathrm{NH}$ polar night jet was somewhat weak, leading to SSW that occurred too often and too early, and resulting in an unrealistically low potential for PSC (Polar Stratospheric Clouds) formation. The latter play a major role in spring-time destruction of ozone.

For this paper we studied the stratospheric time series of many of the years within the 21 year CMAM data-set, as well as assessing in parallel the wavelets for middle atmosphere altitudes, before choosing a winter (31-32) and years (socalled 31,32 ) for inclusion here. These years are generally typical of the entire data set, and they are therefore also used for the tidal and PW characteristics at middle and high latitudes that are discussed later. For the radars and MetO, years 2001 and 2002 (with the 2001-2002 winter as focus) were chosen due to availability, quality and quantity of data, and because the year was also generally typical in terms of PW and tidal seasonal variations and their related height structures. However, it will be seen to have one unique mid-winter characteristic. These choices of data-interval are further discussed and justified in Sect. 5.4 (Interannual Variability).

In Fig. 1 we show the MetO and CMAM temperatures for four altitudes from near 20 to $50 \mathrm{~km}$. In this year, observed disturbances do not occur until late December-early January, with another warming pulse late in February. Similar behaviour occurred at several other $70 \mathrm{~N}$ longitudes, and these two warmings also existed in the mean zonal values, suggesting a major SSW event. In fact Naujokat et al. (2002) consider this winter, along with 1998/99 and 1987/88, as being interesting due to them each having two SSW events. The existence of two SSW in one winter is highly unusual, and if one calls the 1987/88 second event a "final warming", the other two years are unique in the Free University Berlin record from 1964. So, indeed, this chosen year was rather special, with a warming as early as late December/January; indeed, we note that by serendipity we have chosen a year with one of the earliest major warmings since 1964, and all others available in the MetO data-set occur later in the winter. However, in contrast, the CMAM time-sequence at Troms $\emptyset$ for model years $31 / 32$ has several disturbances, or warmings, which are seen as departures from the smooth trend toward lower values that began in the late summer and ends in the late spring: these occur as early as November. Most other CMAM years are similar. Notice also that the minimum values in the CMAM stratosphere are significantly higher (10$30 \mathrm{~K})$ than in the data-driven MetO product.

Thus this figure is consistent with the CMAM study of Chaffey and Fyfe (2001), with frequent warming pulses and warmer stratosphere at high latitudes. Since only one location was available for this experiment, it is not known if these warmings were seen at all longitudes, and so if any of them were true major SSW.

The PW and/or low frequency wind activity is not shown here, but it is large for model year 31-32 (and generally so for the other years) in the CMAM's winter $70 \mathrm{~N}$ stratosphere: this is consistent with enhanced poleward flows, warmer polar temperatures and a weaker polar vortex, which provides a greater likelihood of modeled SSW. The new CMAM data, 


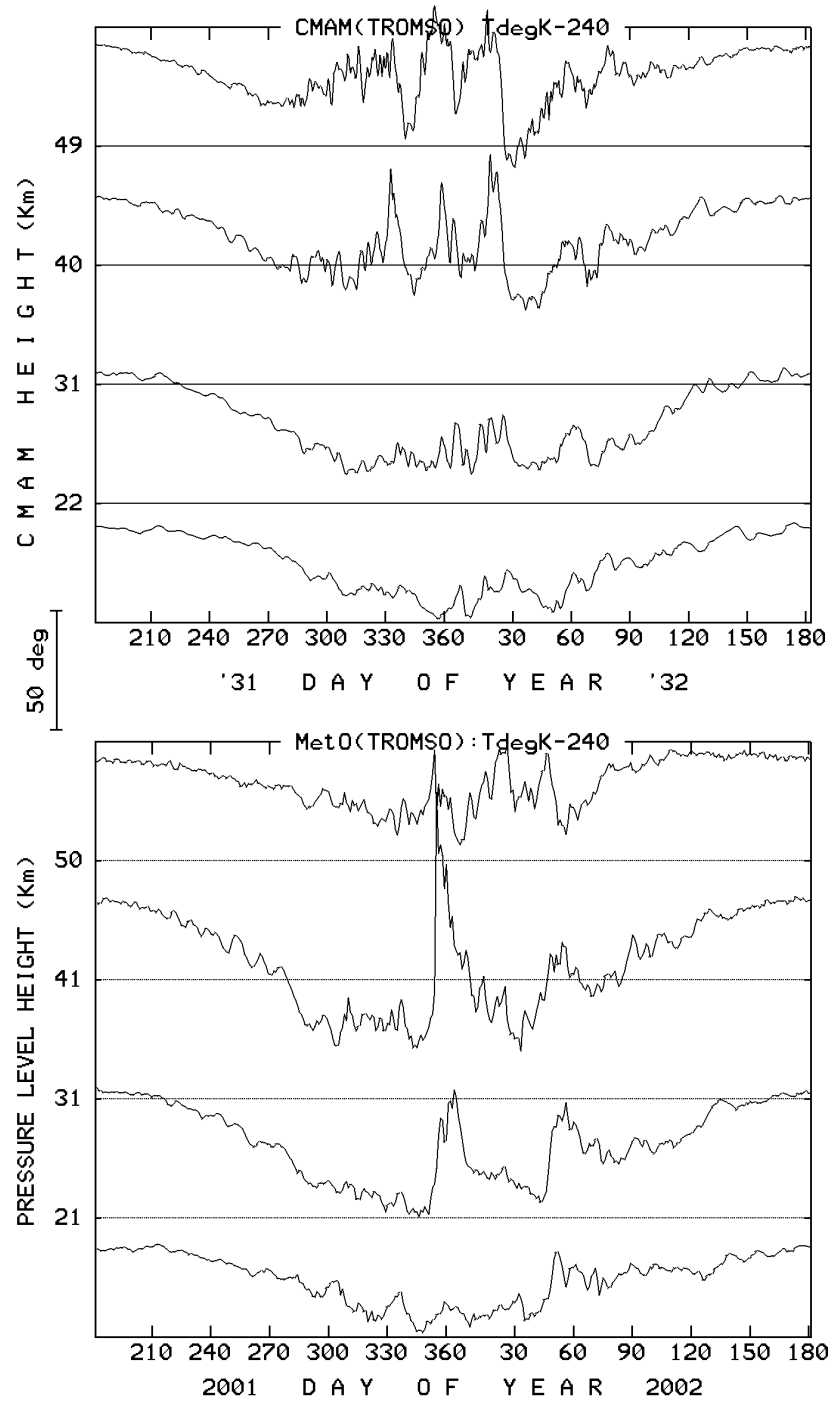

Fig. 1. Time sequences of stratospheric temperature data from the United Kingdom Meteorological Office (MetO, or sometimes UKMO) and the CMAM model. The location is Troms $\varnothing\left(70^{\circ} \mathrm{N}\right)$ and the years are 2001/02 and model-years 31/32.

influenced by internally calculated ozone, has not changed this scenario. A more global assessment, involving more longitudes, of PW activity within CMAM is desirable; the strength of the zonal vortex from $30-100 \mathrm{~km}$ requires a combination of PW and GW to establish realistic middle to high latitude summer and winter vortices, with the GW closing or reversing the vortex in the mesosphere. If PW effects are too large, then GW fluxes required to establish realistic mesopause temperatures will be different from the "real" or typical atmosphere. There will be implications for the modeled tides and planetary waves at MLT altitudes.

\section{Spectra of winds: wavelets and periodograms}

Here we provide wavelets for the complete set of MFR locations, including the $40 \mathrm{~N}$ CUJO network. The contour plots are again for the year 2001/02 (MFR) and model year 31/32 (CMAM), and cover 12 months of the split (winter-centered) year and periods from 6-h to 30 days. (The varying time intervals for each spectral estimate are approximately 3 times the period of the respective wave). Figure 2 is for $85 \mathrm{~km}$, and brief comments are made upon spectra at $50 \mathrm{~km}$ (using MetO) and $76 \mathrm{~km}$ (MFR).

We consider, firstly, the general strengths of the spectral features in Fig. 2. The CMAM 24-h tides are larger than the MFR at Hawaii (at which latitude the diurnal tide dominates the tidal fields, Paper 1), and the CMAM 12-h tides are often (e.g. winter) larger than the MFR at Saskatoon and Troms $\varnothing$ (where the semi-diurnal tide dominates the tidal fields, $\mathrm{Pa}$ per 1). In both cases the differences are typically two color (contour) steps $(6 \mathrm{~dB}$, a factor of 2$)$. We remind the reader at this stage that the MFR winds near $85 \mathrm{~km}$ are probably small by up to circa $2 \mathrm{~dB}$ (Sect. 2), which often would involve a change of one color step, but even with that, the tidal amplitude generalizations above are still true. Considering the PW (i.e. low frequency) portion of the spectra, the CMAM intensities have already decreased from their maxima near $67 \mathrm{~km}$ (wavelet not shown), and the MFR values are, at most locations, larger than modeled by up to one color step ( $3 \mathrm{~dB})$. Again allowing for the small-bias (circa $2 \mathrm{~dB}$ ) in the MFR winds near $85 \mathrm{~km}$ (Sect. 2), the "corrected" observed PW intensities would be up to two color steps larger (factor of 2). These differences are made more quantitative in Sects. 5 and 6.

There are evidently also seasonal differences between the CMAM and MFR tidal amplitudes at $85 \mathrm{~km} \mathrm{e.g.} \mathrm{the} \mathrm{modeled}$ 12-h tides at Saskatoon have a stronger maximum in wintercentred months (November-March) than is observed, and the modeled monthly 24-h tides at Christmas Island vary quite differently from observed. Regarding PWs, both CMAM and MFR evidence a clear preference for longer periods in winter-centered months. Peaks in the 10-20 day periods can be associated with the Rossby or "normal" modes (the socalled 10- and 16-d PW). Again, these differences between modeled and observed values will become more obvious and quantitative in the tidal and planetary wave contour plots (height versus time) of the next sections.

The higher spectral resolution available for a periodogram analysis proves to be useful in further typifying the tidal features. We have chosen the autumn days (SeptemberNovember) for the middle latitude location of Saskatoon, where the 12-h tide often dominates (Fig. 3). 12 day intervals are slid by 2 days to show the spectral features as they evolve [this compares with $\sim 3$ day intervals for the tidal features in the wavelets.] The MFR spectra reveal the normal burst of 12-h tidal energy regularly observed at this time (Manson et al., 2003); here the spectral peak is clean with no indication 


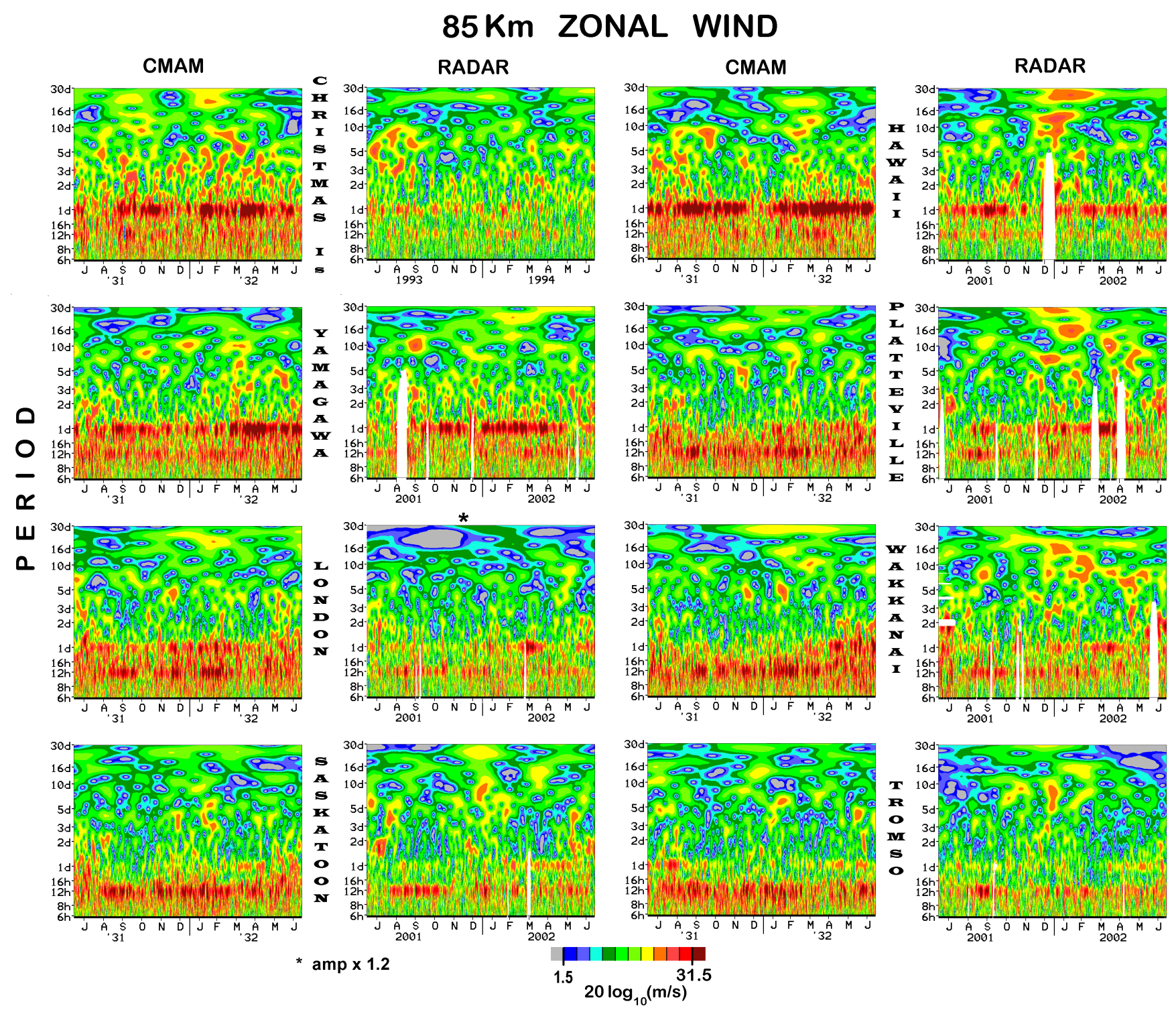

Fig. 2. Wavelet analysis of $85 \mathrm{~km}$ zonal wind data from the MF radars and from the CMAM model: the locations are those of the MF radars, Christmas Island to Troms $\emptyset$. The years are the same as for Fig. 1: 2001/02 and model-years 31/32. Data amplitudes from London's MFR are multiplied by a factor of 1.2 due to a bias in the local analysis.

of other peaks or side-lobes near the main feature. However, for CMAM (again using model year 31) after the autumn burst (which is rewarding and unusual to see successfully modeled), the spectral noise from 16 to $10 \mathrm{~h}$ is considerable. Side-lobes in this spectral region have been shown to be largely due to non-linear local interactions between the tides and 10- and 16-d oscillations associated with Rossby PW activity (Manson et al., 1982). As the spectra show, the PW activity at these times was low. Such spectral behaviour is seen at all locations, and for the 24-h tide at low latitudes. This is interesting and perplexing. It raises the possibility that the GW-tidal interactions are modifying the phases and hence apparent frequencies of the 12-h tide (Walterscheid, 1981).

\section{Tides: seasonal variations in the mesosphere}

In our earlier Papers 1 and 2 using CMAM data, contour plots (height versus latitude), were assessed for the middle month of each season (January, April, July, October). Locations ranged from Christmas Island to Troms $\varnothing$, with only Troms $\varnothing$ being outside a restricted longitudinal range from the Pacific to western North America). 12- and 24-h amplitudes and phases were shown. Briefly, the modeled tides had major features similar to those observed: the 24-h tide dominated at low latitudes, with maxima in equinoxes and short wavelengths $(25-30 \mathrm{~km})$; there were generally long wavelengths $(\sim 100 \mathrm{~km})$ at high latitudes. The 12-h tide dominated at higher latitudes $\left(>40^{\circ}\right)$, with winter amplitudes at $85 \mathrm{~km}$ 


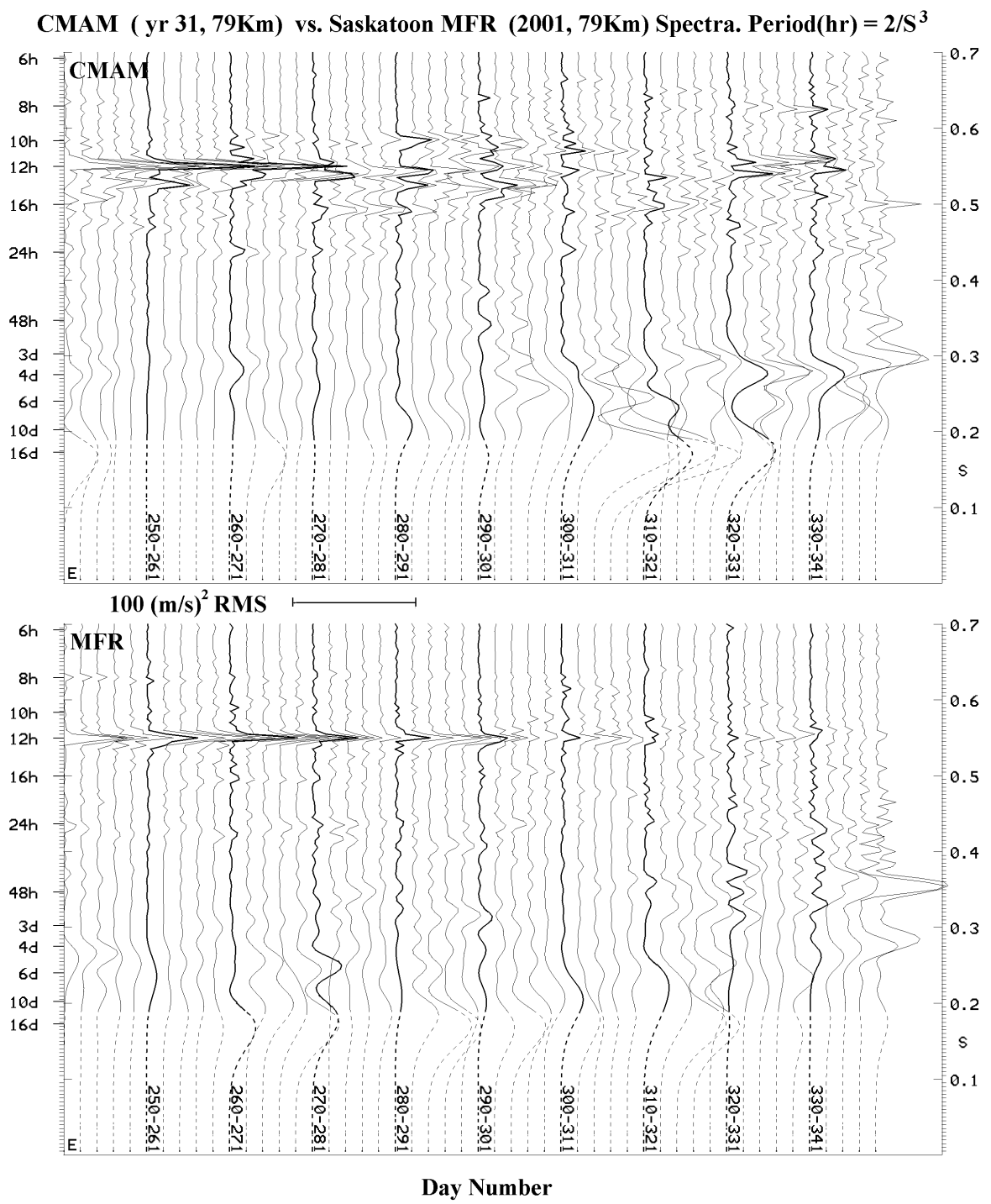

Fig. 3. Spectral analysis of zonal wind data from the MF radar at Saskatoon and from the CMAM model. See Sect. 2.4 for the analysis method and discussion.

above $10 \mathrm{~m} / \mathrm{s}$, and wavelengths of moderate size $(50 \mathrm{~km})$; wavelengths were longer $(\sim 100 \mathrm{~km})$ in summer, and 40 $80 \mathrm{~km}$ in the equinoctial months of April and October; amplitudes were smaller $(5-10 \mathrm{~m} / \mathrm{s})$ in the chosen non-winter months.

However, some significant differences were also found between the model and the observations, involving the 4 chosen seasonal months, latitude and altitude. There were also some differences in the modeled tides and mean winds, depending upon the use of the Hines or Medvedev-Klaassen GW parameterizations. We summarized these as follows: the modeled 12-h amplitudes and phases were in generally good agreement with the MFR observations, with the Hines parameterization showing more phase irregularities than the Medvedev-Klaassen parameterization; the modeled 24-h am- plitudes for equinoctial low latitudes and summer middle latitudes were significantly larger than observed near 82 and $73 \mathrm{~km}$, respectively, allowing for the probable MFR speed bias; and modeled 24-h phase-gradients (wavelengths) and absolute phases, while similar to observations at low and high latitudes, differed quite significantly at middle latitudes $\left(<52^{\circ} \mathrm{N}\right)$. In the $24-\mathrm{h}$ case, there were significant differences at certain times and latitudes for tides from the two parameterization schemes.

\subsection{Latitudinal contour plots (latitude verses height)}

We formed such seasonal contours (middle months) for several years of the 21 now available, and noted that although the major features were robust, the inter-annual variability 
was of similar magnitude to that found earlier between the two parameterizations when applied to a single year. The phase contours for different years were often smoothly varying with latitude, suggesting that the earlier claim (Paper 1) that the Hines parameterization produced more phase discontinuities may have been based upon a small data sample. The most useful presentation for this format, where relatively modest changes at a given location can lead to significant changes (visually very evident) in the continuity of latitudinal contour-patterns, was therefore determined to be an average of the 21 years for each of the 6 locations chosen: Christmas Island, Hawaii, Yamagawa, Platteville, Saskatoon, and Troms $\varnothing$. (3 Pacific, 2 Canada-U.S., 1 Scandinavia). The average amplitudes and phases are from the vector means of the tidal vectors for each year. The zonal wind plots for both tides, with amplitudes and phases, are show in Fig. 4; the phase structures shown are common to many of the individual years of 21, and the meridional plots (not shown) are very similar in structure and values (the amplitudes in the equinoxes are less than $5 \mathrm{~m} / \mathrm{s}$ smaller). As noted earlier, the MFR data do not provide useful complementary plots due to data gaps (time or height, Paper 1), so the discussion below will refer to our earlier CMAM papers, and on occasion to the seasonal contour plots (height versus time, below) for Saskatoon and Hawaii.

The contour plots of Fig. 4 are very similar in general structure, amplitudes and phases to those from the previous CMAM experiments (Paper 1, with non-interactive chemistry), so that the major features of similarity with observations are again clearly evident, as are the differences. These amplitude differences will be considered in more detail in Sect. 5.2.

As in Papers 1 and 2, and especially in the equinoxes, the modeled vertical phase gradients of the 24-h tide in Fig. 4 change from large $(\lambda \sim 22 \mathrm{~km}$ ) at low latitudes to small ( $\lambda$ of order $100 \mathrm{~km})$ at latitudes near Saskatoon $\left(52^{\circ} \mathrm{N}\right)$ and beyond; this is reasonably consistent with the expected dominance of the $S(1,1)$ and $S(1,-1)$ Hough modes $(\lambda \sim 28 \mathrm{~km}$ and $>100 \mathrm{~km}$ ). Since the general phase-behaviour shown in Fig. 4 is similar to that previously modelled (as in Papers 1 and 2), and therefore CMAM vertical phase-gradients at middle latitudes will again differ from observations, we will discuss this matter in more detail in Sect. 5.2 using tidal contour plots for two locations.

Regarding the tidal characteristics, it will be shown below that the seasonal changes (modelled and observed) are quite large, and other maxima appear in tidal contour plots when higher temporal resolution (circa 10 days) is used. One month from a season is not enough to characterize seasonal variations. At this point we remark that the similarity of tidal characteristics between those in Fig. 4 and those in Paper 1 is rather surprising given the interactive-chemistry of this present experiment. Modelled ozone distributions, with more realistic vertical distributions (de Grandpré et al., 2000), were expected to provide more realistic forcing of the tides, in comparison with those from a model with imposed ozone distributions; again, the 12-h tide, for which ozone dominates the forcing, might have been expected to show more changes than the 24-h tide. The changes in ozone have evidently been small at those heights responsible for tidal forcing of the various Hough modes.

\subsection{Annual contour plots (height vs. time) at Saskatoon $\left(52^{\circ} \mathrm{N}\right)$ and Hawaii $\left(22^{\circ} \mathrm{N}\right)$}

We now move to comparisons of CMAM and MFR tides for two locations (Hawaii and Saskatoon) which are, respectively, dominated by the diurnal and semi-diurnal tides. For the first time we can show 10-d resolution for the modeled height-time contour plots throughout the year. The selection of year 31 from the CMAM set of 21 years was made because it has been featured in the previous figures, and because in the contour plots of this section the inter-annual variability leads to quite small changes in seasonal and altitudinal patterns of amplitude and phase changes, at these two locations i.e. changes that are small compared to those that will be demonstrated between CMAM and the observations. In this, year 31 is quite typical tidally, as is the observed year of 2001 for the MFR data. However, there may still be significant inter-annual variability of amplitude within the regions of local amplitude maxima, and these will be discussed below at appropriate points, as well as in Sect. 5.4.

In Figs. 5 and 6 we show a comparison of CMAM and MFR tidal amplitude and phase data respectively, for 365 days, using harmonic $10-\mathrm{d}$ fits. The analysis was described in Sect. 2. Color/contour scales are chosen for best comparisons of the extreme differences between 52 and $22^{\circ} \mathrm{N}$. Please note that the radar data are extended to $97 \mathrm{~km}$ to demonstrate the evolution into the lower thermosphere, while CMAM is limited to $88 \mathrm{~km}$, and is best considered to $82 \mathrm{~km}$, to avoid boundary effects.

For the 24-h (diurnal) tide at Hawaii (Fig. 5), modeled equinoctial values at $82 \mathrm{~km}$ reach maxima of $38 / 53 \mathrm{~m} / \mathrm{s}$ in April/September for the NS component, and $48 / 44 \mathrm{~m} / \mathrm{s}$ in April/September for the EW component. Meanwhile observed values in February-March/September are 19/22 m/s for the NS, and $15 / 19 \mathrm{~m} / \mathrm{s}$ for the EW. We also calculated the mean values of the equinoctial features for five years of CMAM and MFR tides and found little difference between those and the plotted values for years 31 (CMAM) and 2001. It is worthy of note that the spring maxima occur about one month later in CMAM plots than in the observed MFR plots. However, using the values above, the ratios of the CMAM/MFR amplitudes range from 2 to 3 . Allowing for a speed bias (small) of 1.3 for the Hawaiian MFR (based on recent comparative data (2005) from Steven Franke) the corrected ratios become 1.5 to 2.3 . We note that the equinoctial maxima values from GSWM-2000 (Paper 2), which were normalized to UARS-HRDI values at $95 \mathrm{~km}$ are also smaller (they are circa $25 \mathrm{~m} / \mathrm{s}$ ) than CMAM at $82 \mathrm{~km}$. 


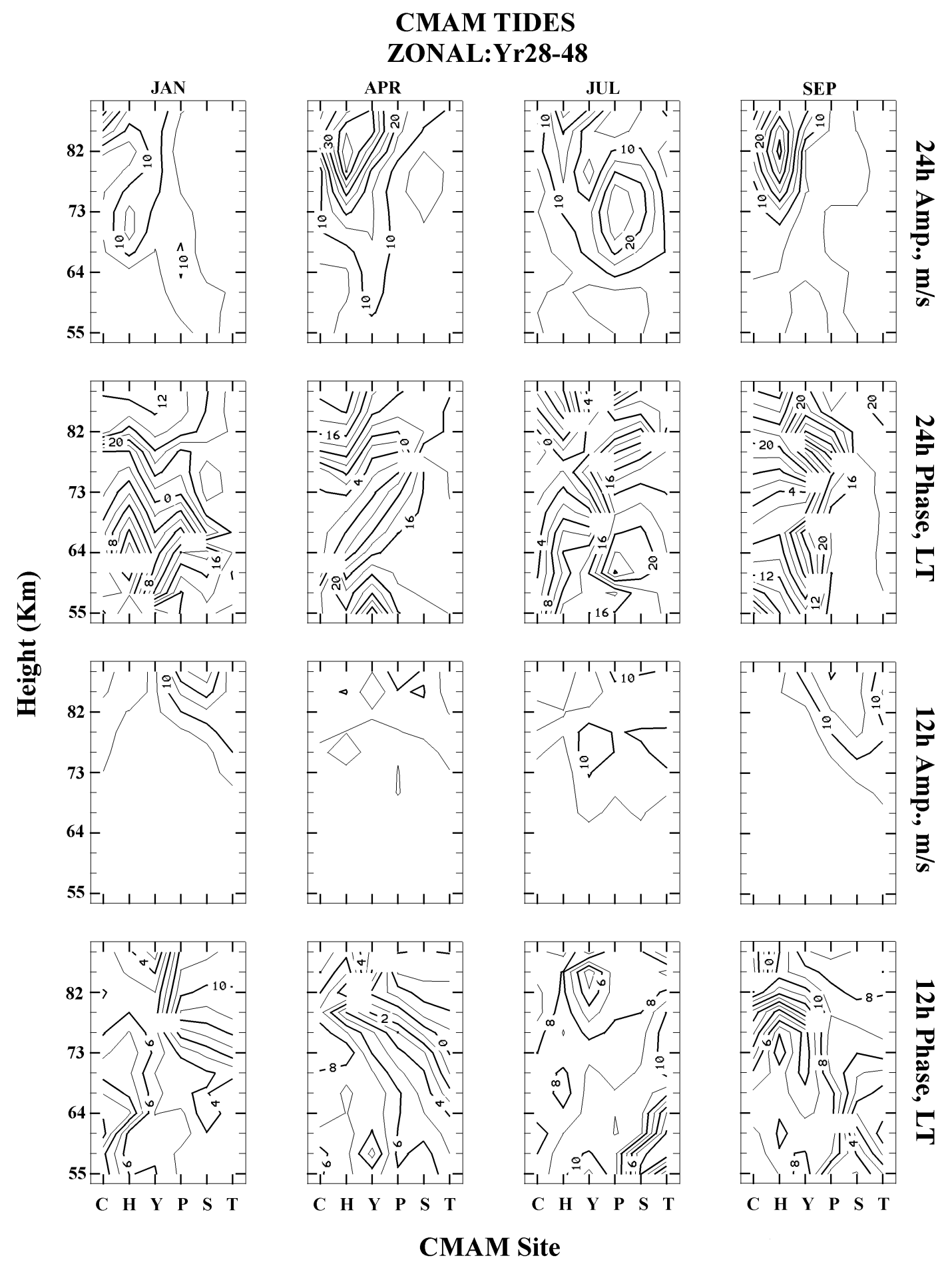

Fig. 4. Latitudinal contour plots (latitude verses height) of CMAM tidal amplitudes and phases (zonal component), which result from harmonic analysis (Sect. 2.4). The locations are Christmas Island, Hawaii, Yamagawa, Platteville, Saskatoon and Tromsø. 21 years of data are used, with model-years 28-48.

A final remark about Hawaiian tides in Fig. 5: the equinoctial MFR values maximize (circa $35 \mathrm{~m} / \mathrm{s}$ ) near $90 \mathrm{~km}$ but are only near $24 \mathrm{~m} / \mathrm{s}$ at $96 \mathrm{~km}$. Certainly the GSWM and
CMAM values shown in Paper 2, and in Fig. 5, continue to increase above $82 \mathrm{~km}$. From Manson et al. (2002c), satellitederived diurnal tidal amplitudes over Hawaii in the autumn 
Saskatoon

NS
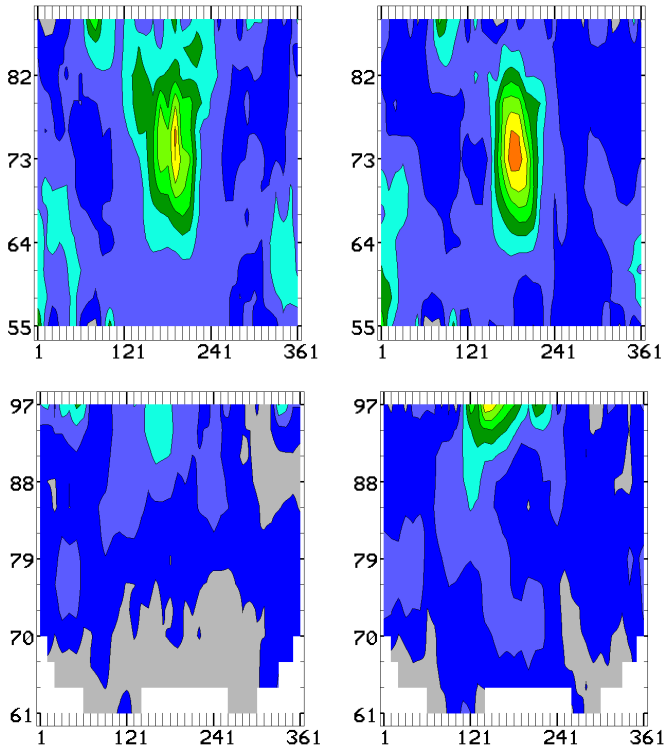

Hawaii

NS

EW

\section{Diurnal Tide Amplitudes}

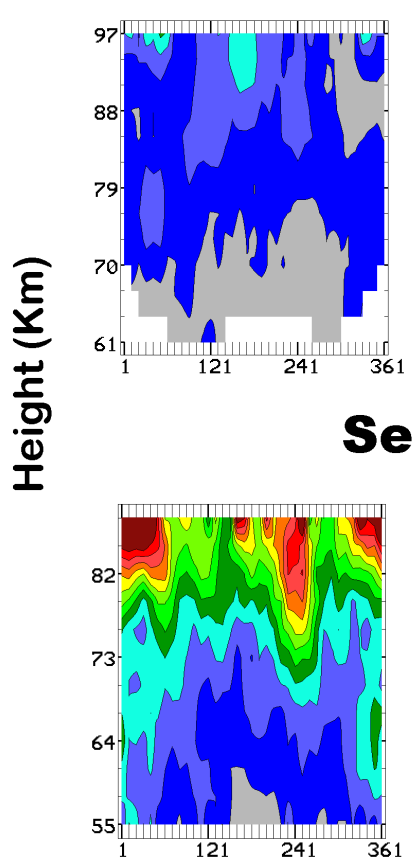

\section{Semi-Diurnal Tide Amplitudes}
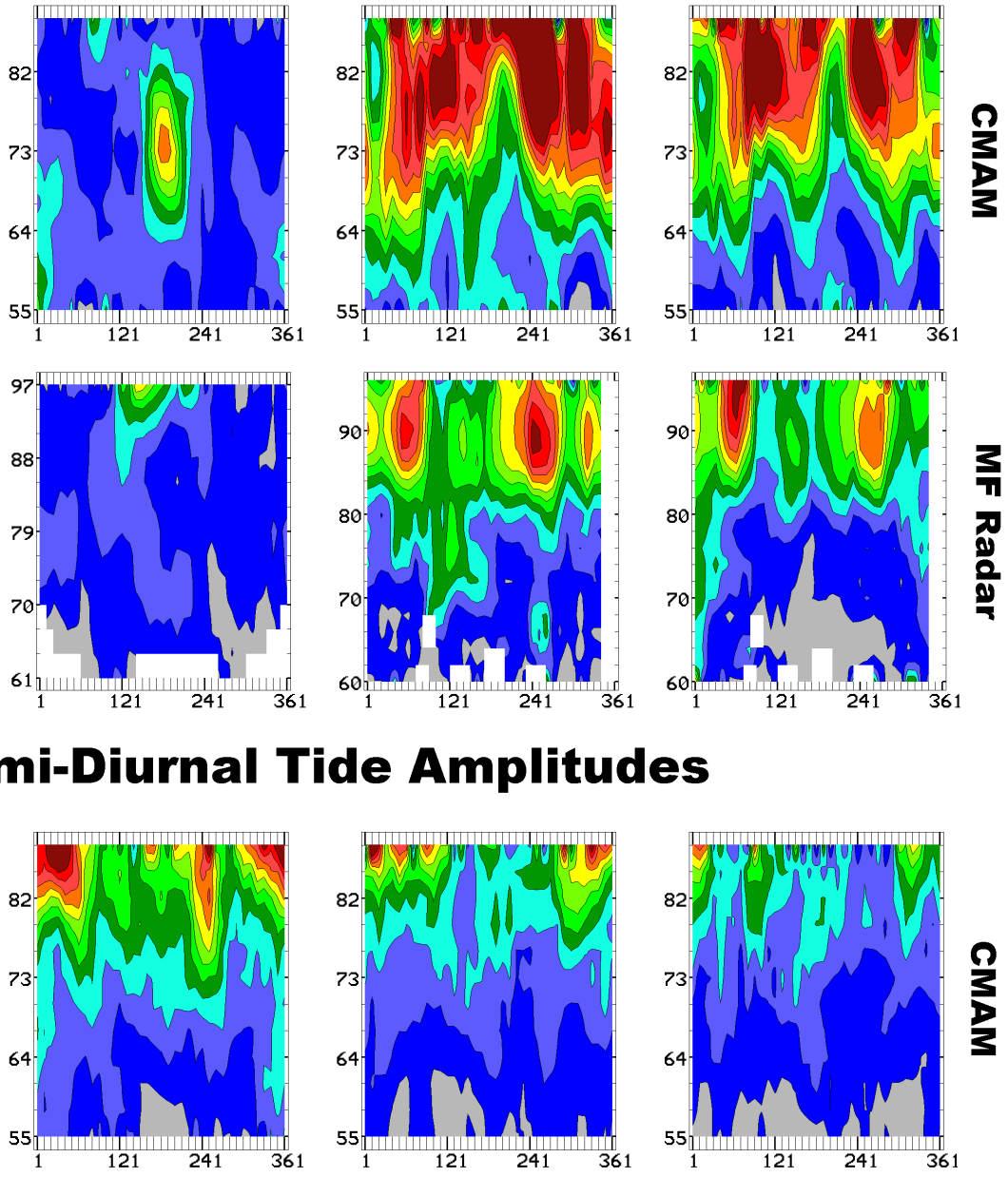
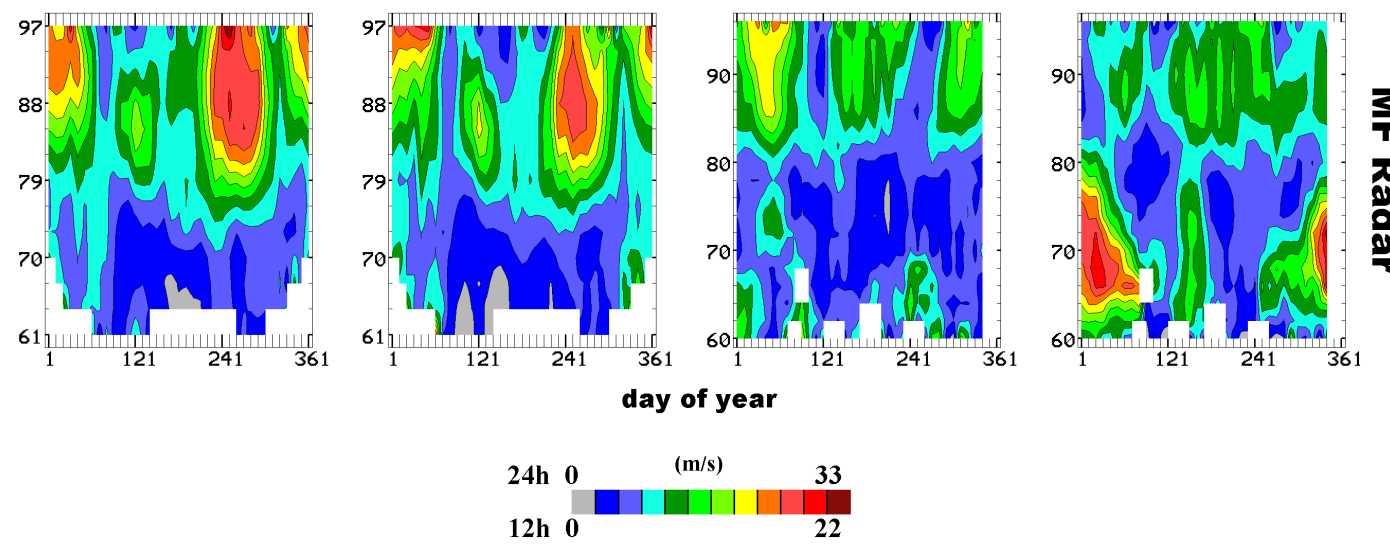

Fig. 5. Annual contour plots (height versus time) of diurnal and semi-diurnal tidal amplitudes resulting from harmonic analysis of CMAM (year 31) and MF (year 2001) radar data for Saskatoon $\left(52^{\circ} \mathrm{N}\right)$ and Hawaii $\left(22^{\circ} \mathrm{N}\right)$, and providing 10-day resolution. Interpolation between data points employs a "bilinear patch" (Sect. 2.4). Zonal (EW) and meridional (NS) components are shown. 


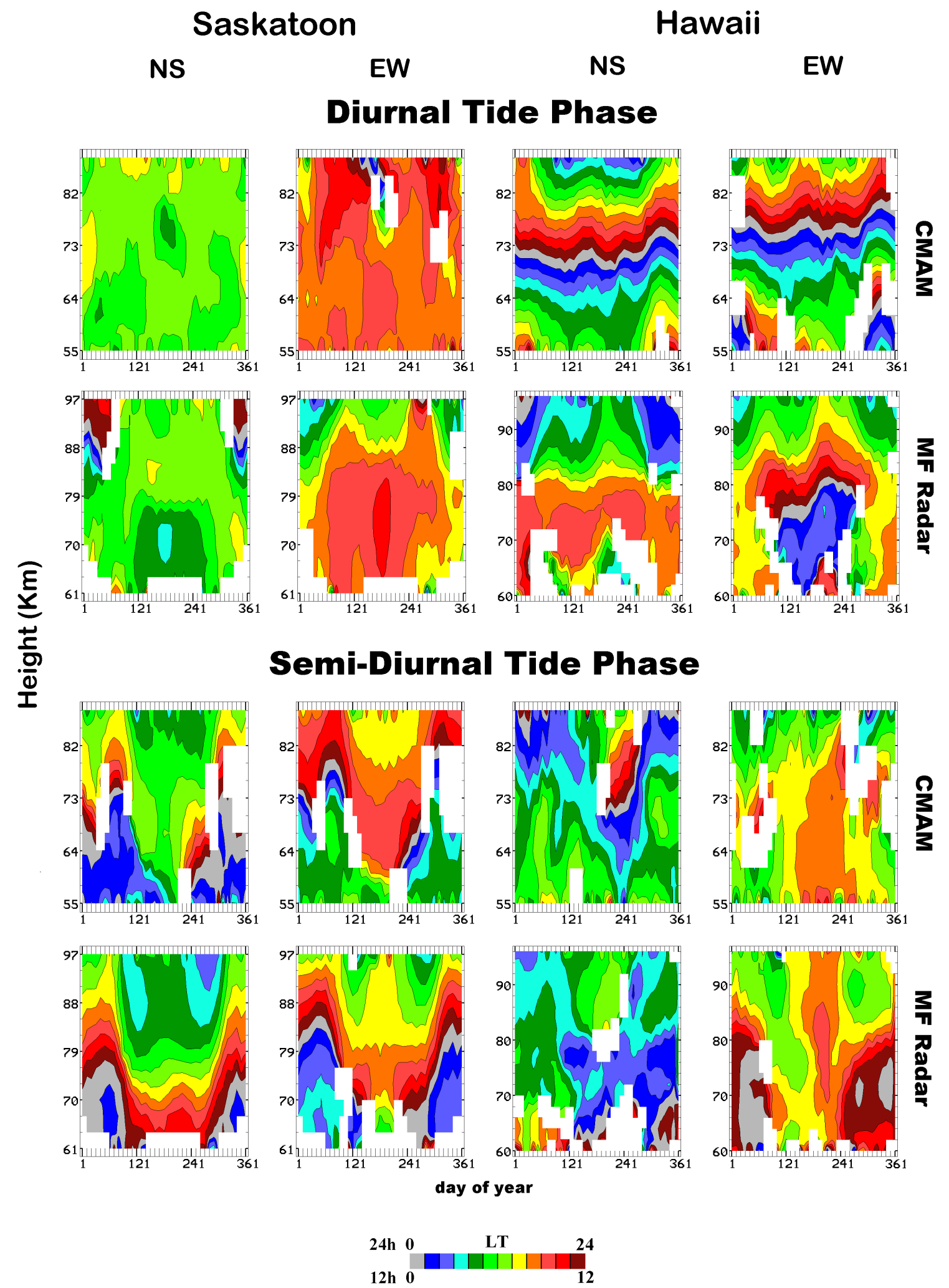

Fig. 6. Annual contour plots (height versus time) plots of diurnal and semi-diurnal tidal phases resulting from harmonic analysis of CMAM (year 31) and MF (year 2001) radar data for Saskatoon $\left(52^{\circ} \mathrm{N}\right)$ and Hawaii $\left(22^{\circ} \mathrm{N}\right)$, and providing 10-day resolution. Interpolation between data points employs a "bilinear patch" (Sect. 2.4). Zonal (EW) and meridional (NS) components are shown. 
are typically $35 \mathrm{~m} / \mathrm{s}$ at $96 \mathrm{~km}$, which provide a HRDI/MFR speed ratio of nearly 1.5. (HRDI: High Resolution Doppler Imager on UARS.) This is the expected speed bias ratio presented in Sect. 2.1, so that the MFR amplitude-decreases above $90 \mathrm{~km}$ in Fig. 5 are artificial (intrinsic to the MFR system).

The remaining diurnal tidal feature occurs in the midlatitudes in summer. At Saskatoon, the modeled $73 \mathrm{~km}$ maxima (circa $24 \mathrm{~m} / \mathrm{s}$ ) are not observed and typical values there are only $\sim 6 \mathrm{~m} / \mathrm{s}$. There are no MFR speed biases, compared with Meteor (MWR) radar, at $73 \mathrm{~km}$, so these interesting differences in Fig. 5 remain.

For the 12-h tide, both CMAM and MFR data demonstrate maxima at the higher latitude location and generally have similar seasonal variations at $52^{\circ} \mathrm{N}$ : modeled/observed winter values near $82 \mathrm{~km}$ are $14-18 / 8-10 \mathrm{~m} / \mathrm{s}$ (beyond the speedbias expectation), and the late-summer to autumn maxima are well modeled (16-20/14-18 m/s). Other models have not shown this dominant feature well (cf. Paper 1, 2; Riggin et al., 2003).

In Fig. 6 we compare the phases for tides, between the latitudes of 52 and $22^{\circ}$, and between the CMAM and the MFR observations. The phases are more revealing than the amplitudes, as they suggest the tidal Hough modes that are dominant. For the 24-h tide, CMAM provides very strong vertical phase gradients $\left(\lambda_{z} \sim 22 \mathrm{~km}\right)$ at Hawaii, and weak gradients $\left(\lambda_{z}>100 \mathrm{~km}\right.$, evanescent) at Saskatoon: as noted earlier, reasonably consistent with $S(1,1)$ and $S(1,-1)$ Hough modes $\left(\lambda_{z} \sim 28 \mathrm{~km}\right.$, and evanescent, respectively). The tidal winds are clockwise rotating, and in quadrature as required for dominant modes. Observationally the contrast in vertical wavelengths is less pure: for Hawaii vertical wavelengths (at $75-90 \mathrm{~km}$ altitude) are closer to $30-32 \mathrm{~km}$ during the summer, and somewhat longer in the winter, again with the components in quadrature; and for Saskatoon they are relatively short in winter $(\sim 50 \mathrm{~km}$ near $85 \mathrm{~km}$ altitude) and irregular in summer (the NS, EW components are out of phase below $80 \mathrm{~km}$, and in phase near $90 \mathrm{~km}$.) These observed features are very consistent with earlier studies (Paper 2), and are not unique characteristics of the chosen year (2001). The observed phase structures are indicative of a mixture of tidal modes, which is also seasonally varying. This is consistent with the longitudinally varying tidal structures and nonmigrating tides shown from the HRDI winds (Manson et al., 2002c, 2004b). Unfortunately, the available CMAM data does not allow for zonal wave-number analysis. Finally the colours for the phase-plots are often similar when compared between CMAM and MFR, which is consistent with the similarities in the phase profiles discussed above (as concluded in Papers 1 and 2).

The above may seem to be overly critical of the ability of CMAM to simulate the diurnal tide, and that impression should be corrected to some degree. It is appropriate to comment on the two papers on the 24-h migrating tide by McLandress $(2002 \mathrm{a}, \mathrm{b})$. They discusses the simulation of the tide in the extended CMAM, mainly at low latitudes $\left(<40^{\circ}\right)$, and notes that the following are reproduced: the semi-annual amplitude variation (near $20^{\circ}$ ); larger tides in March/April than September/October (especially for the EW component) and generally very good agreement with amplitudes observed by WINDII at $96 \mathrm{~km}$; a 4- to 6-h shift in phase from winter to summer $(\mathrm{NH})$; and other SH-NH differences we need not comment upon. Indeed the CMAM data shown in Figs. 5 and 6 also show these features, which are often not revealed by other models. Other models e.g. GSWM-2000, depend upon GW drag or variations in eddy diffusion to produce this 6 month variation; while the author goes on to demonstrate that the effects of parameterized GW and planetary waves are less important than the effects of both heating (maximizing at the equator in the equinoxes) and mean winds (latitudinal shears in the summer mesospheric easterlies).

The difference between observations and model that we have demonstrated here are at a further level of subtlety: monthly vertical phase gradients at a particular location (Hawaii) where non migrating tides become an issue (Manson et al., 2004b) in modifying the pure $\mathrm{S}(1,1)$ mode, (that mode is dominant in satellite data when longitudinally averaged); and assessments of vertical phase gradients at higher latitudes $(\geq 40 \mathrm{~N})$, where the decay of the $S(1,1)$ mode with latitude and the growth in influence of evanescent modes becomes important. These features are robust and are not a feature of the chosen year (2001). We discuss the decay of the $S(1,1)$ mode in the next section where longitudinal effects near $40^{\circ}$ are considered.

Now, considering the 12-h tide in Fig. 6, the observed and modeled tidal phases are rather similar, as the color ranges for each component and location are evidently similar, especially at $52 \mathrm{~N}$. CMAM provides medium wavelengths $\left(\lambda_{z} \sim 50 \mathrm{~km}\right)$ for Saskatoon, albeit with somewhat irregular gradients in height and time, during the winter, and longer or evanescent structures in summer above $\sim 60 \mathrm{~km}$ altitude; the phase gradients are rather irregular in height and time at Hawaii, with wavelengths ranging from short $(\lambda \sim 50 \mathrm{~km})$ to long $(>100 \mathrm{~km})$. The Saskatoon winter tidal components are in quadrature. Observationally, the phase structures at Saskatoon are very regular, again with medium wavelengths ( $\sim 40$ $45 \mathrm{~km}$ at $70-97 \mathrm{~km}$ ) in winter, but now with short/long wavelengths $(\sim 30 />100 \mathrm{~km})$ below/above $80 \mathrm{~km}$ altitude in summer; while for Hawaii the wavelengths are variable in time and height (and between components), as modeled. (The NS Hawaiian contour plot is very similar to the model, while the winter-EW differs strongly in the low altitude regions of large MFR amplitudes (Fig. 5)). Overall, and as in the first CMAM experiment (Papers 1,2) the 12-h tide is better simulated than the 24-h.

\subsection{Longitudinal variability over CUJO}

Although the high temporal resolution CMAM data were not available over a full range of longitudes at any latitude, 


\section{Diurnal Tide Phase: CMAM vs. RADARS Meridional}

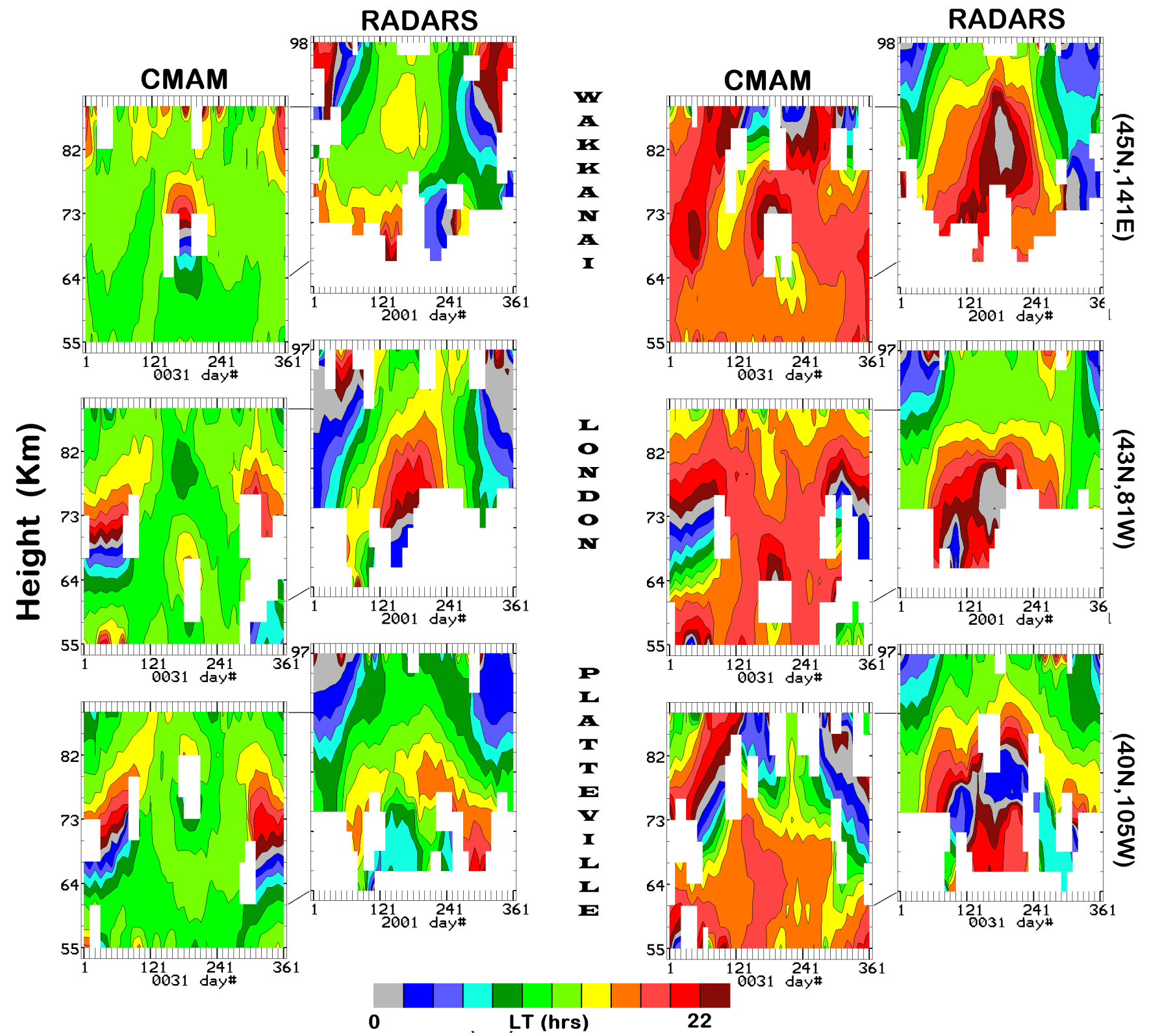

Fig. 7. Annual contour plots (height versus time) of diurnal (24-h) tidal phases for the three CUJO network locations near $45^{\circ} \mathrm{N}$, from both the MF radar observational systems and from CMAM. Zonal (EW) and meridional (NS) components are shown.

data for the CUJO network were provided. We have already demonstrated, using MFR data, that the longitudinal variability (London, Platteville and Wakkanai) of the wavelets (tidal to planetary waves) is significant (2000-2001) and that non migrating tides (NMT) are quite evident (Manson et al., 2004c). We have also shown, in this study, wavelets for 2001-2002 for these locations, and the differences between Eastern Canada and Japan were again evident (Fig. 2). Here we show the annual tidal contours (height versus time) for these three locations from both the MFR observational systems and from CMAM, and for 24 and 12-h (Figs. 7, 8).

Considering the 24-h tide (Fig. 7), the observed phase gradients are strikingly different across CUJO, especially in summer for NS component. However, the CMAM variations are also considerable at particular heights and times. The global HRDI analysis evidenced strong NMT activity 


\section{Semi-Diurnal Tide Phase: CMAM vs. RADARS Meridional}

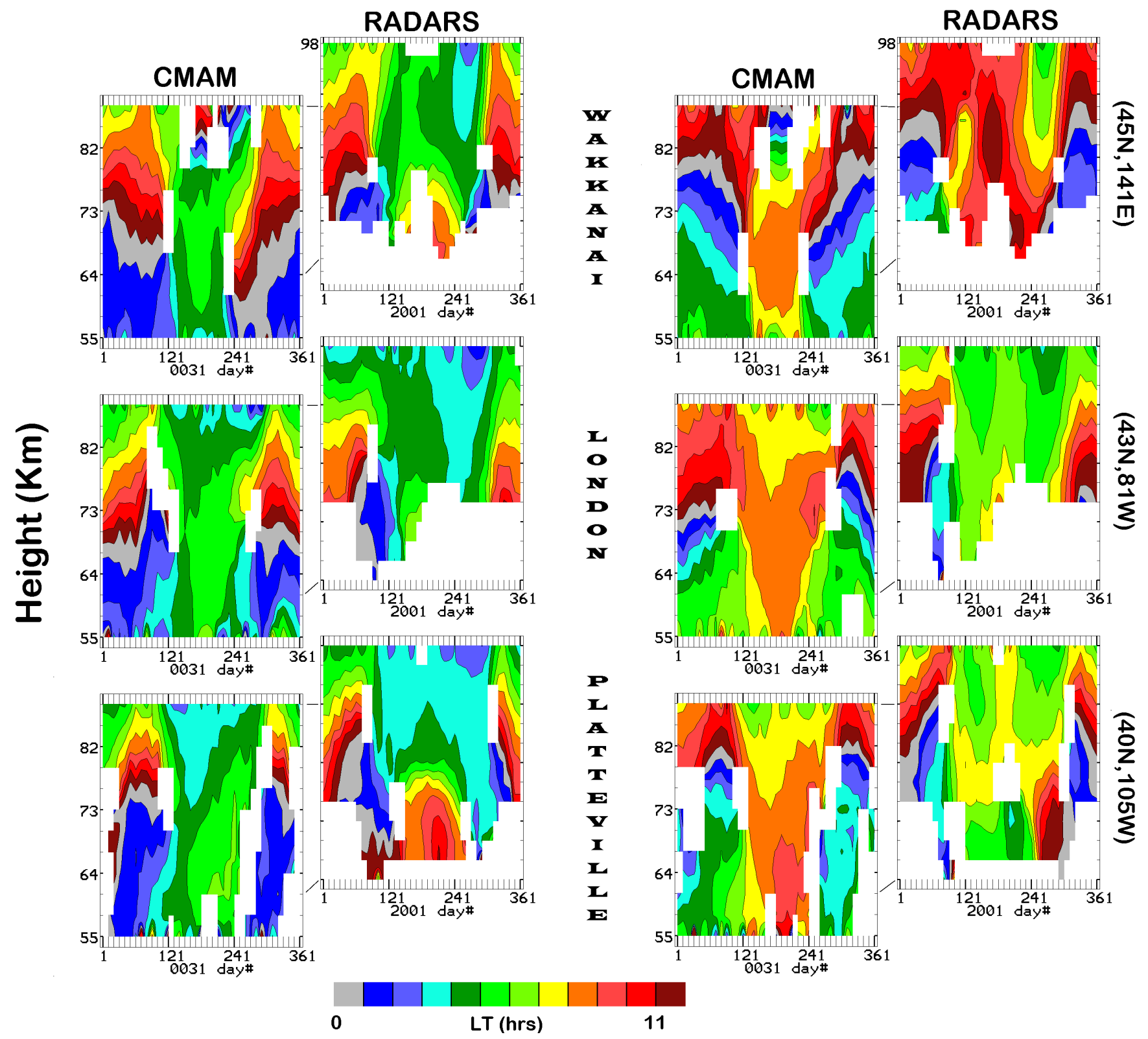

Fig. 8. Annual contour plots (height versus time) of semi-diurnal (12-h) tidal phases for the three CUJO network locations near $45^{\circ} \mathrm{N}$, from both the MF radar observational systems and from CMAM. Zonal (EW) and meridional (NS) components are shown.

(Manson et al., 2004b) especially at wave-number -3 (eastward propagation), which was associated with the observed longitudinal structure (amplitude and phase) of the tide (wave-number 4). There are also substantial differences between model and observations at each site, (the plots are vertically offset so comparisons are easily made) from which the observed strong vertical gradients indicate a larger influence of $S(1,1)$ mode than modelled. The observed influence of the $\mathrm{S}(1,1)$ was much less at Saskatoon $\left(52^{\circ} \mathrm{N}\right.$ versus $40^{\circ} \mathrm{N}$, Fig. 6). Modelling and theoretical studies show that the dissipation associated with eddy diffusion increases the vertical wavelength of the $S(1,1)$ mode in the mesopause region, and broadens the tidal structure to higher latitudes: coupling into the $\mathrm{S}(1,-2)$ and $(1,-1)$ modes occurs as the $\mathrm{S}(1,1)$ mode is damped (Vial and Forbes, 1989). 


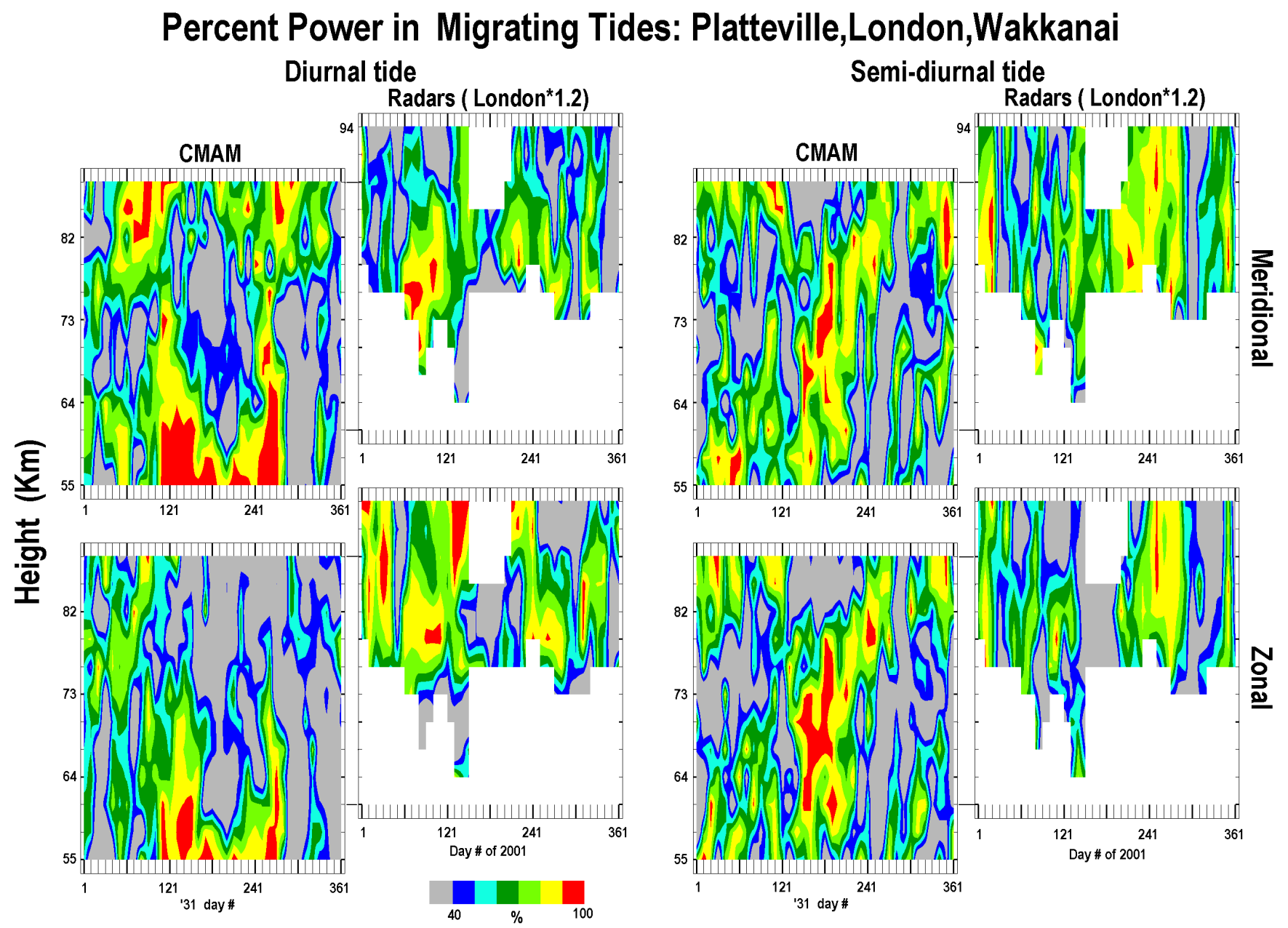

Fig. 9. The vector-differences between the measurements and the fit of a wave equation for the three CUJO MF radars, and for CMAM at those locations, have been calculated and expressed as power: this unfitted power represents the non-migrating tides (plus noise). The wave equation is applied for both the diurnal and semi-diurnal migrating tides $(\mathrm{m}=1,2)$. As in Fig. 2, data amplitudes from London's MFR are multiplied by a factor of 1.2 due to a bias in the local analysis. Red represents almost total dominance of the migrating tide. Zonal (EW) and meridional (NS) components are shown.

Finally, for the 12-h tides (Fig. 8), there are evidently generally strong similarities between the three CMAM contours; for both components, the plots are offset vertically so comparisons are more easily made. The observations show somewhat greater longitudinal differences in phase e.g. compare the colours of early and late winter months above $90 \mathrm{~km}$ (EW and NS components) for Wakkanai and London, and also the colour-differences in the summer months for both components. These observed phase differences across CUJO are consistent with our analysis of HRDI winds, which evidenced significant longitudinal semi-diurnal tidal structures and the related NMT components (Manson et al., 2004b); these are thought to be due to orographic-related solar-forcing and stationary planetary waves $(n=1)$. Ward et al. (2005) have published results from the extended CMAM version. The NMT compare well in terms of amplitude with existing observations e.g. HRDI-UARS, although a phase error renders the wave-number 2 features in their Fig. 2 incorrect (W. Ward, private communication) and a correction is in process. Finally, notice that the differences between model and observations at each site in CUJO are quite noticeable, consistent with some differences in tidal mode-composition. E.g. the presence of a higher order mode, which is consistent with the large observed phase gradients, at low heights in summer.

The above has been based upon visual comparisons, and color-pattern recognition: the differences show up very well. However, an alternative quantitative measure of longitudinal change is now described. The wave equation for the diurnal and semi-diurnal migrating tides $(m=1,2)$ is fitted to the data from the three CUJO sites (CMAM or MFR). The vector differences between the measurements and the fit are then 


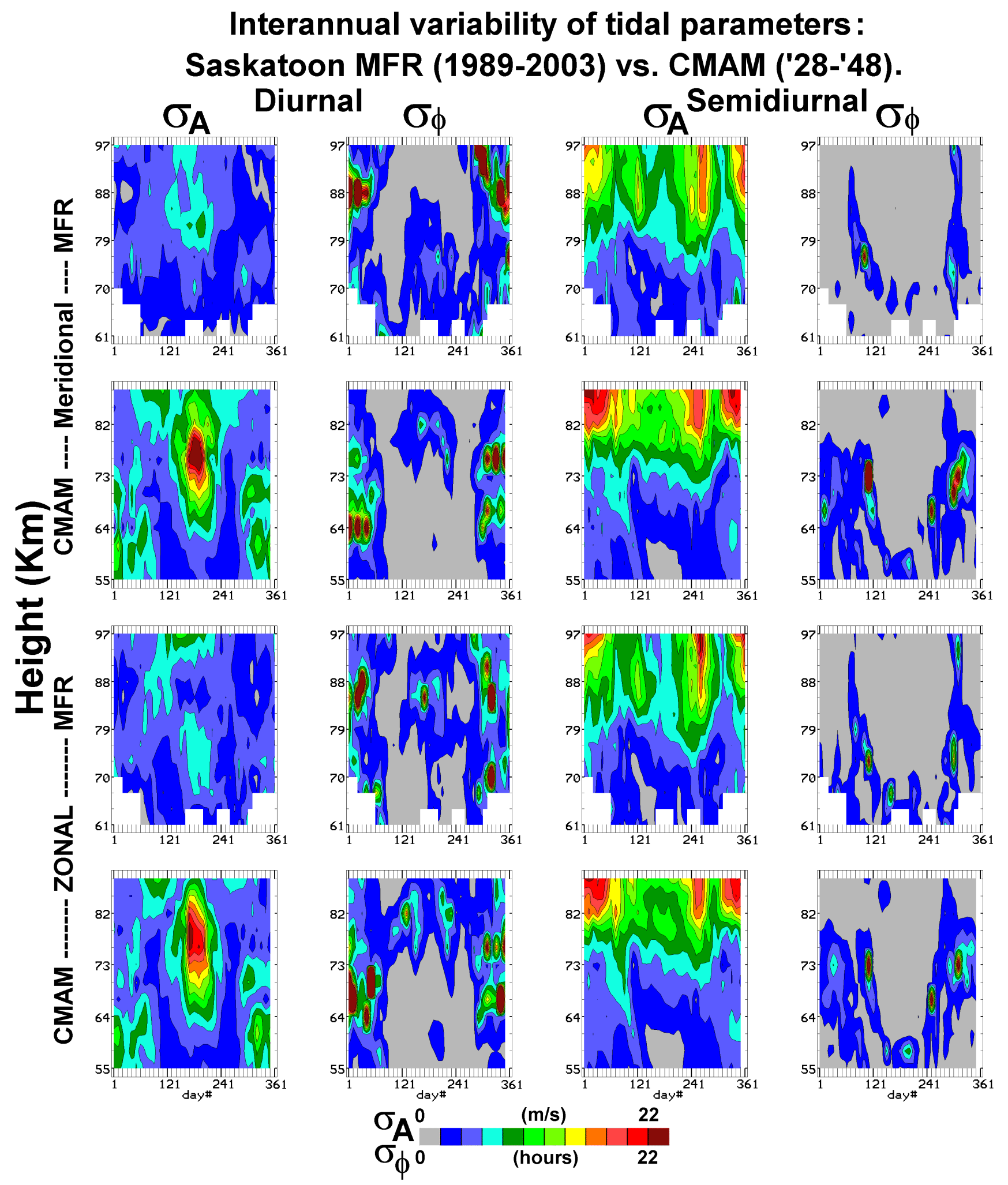

Fig. 10. Interannual variability of tidal parameters as represented by the standard deviations of the tidal (24-, 12-h) amplitudes and phases for both components (zonal, meridional) and for CMAM and the MFR at Saskatoon $52^{\circ} \mathrm{N}$ : 21 years of CMAM are used, and 15 years of MFR. Zonal (EW) and meridional (NS) components are shown. 
calculated, and expressed as power: this unfitted power represents the noise and non-migrating tides. In Fig. 9, red (90$100 \%$ ) represents almost total dominance of the migrating tide, while greens and blue indicate non migrating tides (and noise). The offset and linking lines again indicate the height interval in common between CMAM and MFR. Given the differences in phase structures between CMAM and MFR in Figs. 7 and 8, it is expected that the regions of migrating tide dominance would also vary in height and time, and indeed they do. For the 12-h tide it is not easy to say which (model or observation) has more migrating tide dominance. CMAM does have considerable yellow and red areas below $76 \mathrm{~km}$ in summer, indicating migrating tide dominance: however the phases there (Fig. 8) show no change with height, while NS observations at Wakkanai and Platteville indicate a very strong gradient and hence a combination of Hough modes $(55 \mathrm{~km}-88 \mathrm{~km})$. These short summer wavelengths below $76 \mathrm{~km}$ were also observed at $52^{\circ} \mathrm{N}$ in Fig. 6. The low altitude and long wavelength summer migrating tide dominance in CMAM (Fig. 9) is therefore unlikely to be a real feature. A similar feature in the CMAM and MFR plots of Fig. 9 is the dominance of the migrating tide (yellow and red) in the region of late summer-fall maximum amplitude above $80 \mathrm{~km}$; this amplitude feature was seen in the annual CMAM and MFR contour plots of Fig. 5, as well as over CUJO.

For the 24-h tide, there is a clear tendency for the migrating tide's dominance in Fig. 9 to occur in the equinoxes for the MFR data, at which time the $\mathrm{S}(1,1)$ mode maximizes at tropical latitudes and extends its influence to CUJO latitudes. The evidence for this was just noted from Fig. 7. While the migrating tide's dominance is also true for CMAM in the meridional NS component, it is not true above $76 \mathrm{~km}$ for the fall's zonal EW component. At this very time, there is no CMAM tidal maximum amplitude evident over CUJO (figure not shown), although one exists for the spring. The dominance of the migrating tide in CMAM extends down to $55 \mathrm{~km}$ for late spring and early fall, but we have no data from the MFR to verify details of that.

\subsection{Interannual variability}

Here we have calculated the standard deviations of the tidal (24-, 12-h) amplitudes and phases for both components and for CMAM and the MFR at Saskatoon (Fig. 10): 21 years of CMAM are used, and 15 years of MFR. Comparisons with the amplitudes of Fig. 5 for a particular year show extraordinary similarity between MFR and CMAM amplitudes and their standard deviations (s.d.). All of the regions of large amplitude in the earlier amplitude plots provide regions of large s.d., as expected if there is strong similarity of position for the dominant amplitude seasonal-height structures yearby-year, and variances are proportional to the magnitude. This indicates that the observed contour plots for year 2001 and modelled year 31 are typical of the 15/21 year data sets. As examples, the late summer-fall 12-h amplitude structures seen above $80 \mathrm{~km}$ in both CMAM and MFR annual contour plots (Fig. 5) has a similar height-date location each year, but the amplitude of the feature evidences interannual variability as indicated by the s.d. maxima; and the unobserved summer 24-h amplitude maxima also provides a striking maxima in the s.d. plots.

The phase comparisons are also interesting. For the 12-h tide, the model and observations (Fig. 10) illustrate that s.d. values are largest during the times and heights of rapid phase change in the spring and autumn (Fig. 6). This is to be expected. However the s.d. values are also large in CMAM during winter for regions near $73 \mathrm{~km}$. The phase changes were large there even during the single sample year of 31 (Fig. 6), since contour-continuity was not achievable (blank areas in the figure). This is a significant difference from observations, and may again indicate $\mathrm{GW}$ interactions with the tidal field (Sect. 4, Fig. 3). However, overall the similarity in these plots between CMAM and MFR data-sources testifies to significant similarities between their respective tidal characteristics at middle-latitudes; and inherently, that interannual variability of tidal amplitude and phase structures is modest. This further justifies the choice of individual years for this study (Sect. 3).

The 24-h tidal phase s.d. contour values (Fig. 10) also demonstrate maxima in regions of greatest observed (MFR) phase gradients (Fig. 6) and in doing so indicate that the observed contour plots for year 2001 are typical of the 15 year data set. There are clear s.d. maxima near $85-88 \mathrm{~km}$ in winter time (this was earlier noted to be due to the influence of the $\mathrm{S}(1,1)$ mode), and in mid summer for the zonal (EW) component where the vertical phase gradients (Fig. 6) are also large.

In contrast the largest s.d. phase values are at lower heights $(64-73 \mathrm{~km})$ for CMAM in winter, whereas the phase gradients for year 31 (Fig. 6) do not have large values. This indicates large inter-annual variability in CMAM at these heights, as there are also amplitude s.d. maxima near there in Fig. 9. These phase variability plots confirm the differences noted earlier between CMAM and MFR-derived tides at middle latitudes.

\subsection{Discussion of the modelled tides in CMAM}

The remarks here are brief. The seminal papers on tidal theory and modelling (e.g. Forbes, 1982a and b) demonstrate the atmospheric characteristics which lead to seasonal and latitudinal variations in the tidal phase-gradients (related to mixtures of Hough modes) and amplitudes. Meridional (NS) gradients in middle atmosphere temperatures and mean zonal winds, along with eddy diffusion processes, lead to Hough mode coupling and additional contributions by these higher order modes to the resulting tidal climatologies. Planetary and gravity waves (Sect. 3) play dominant roles in establishing these wind and temperature fields. Changes in ozone and water vapor distributions (height and latitude) also directly 
force different Hough modes in various seasons and during disturbed conditions e.g. SSW. In so far as CMAM, or any generic GCM, have globally varying characteristics of winds, temperatures, ozone or water differing from the real atmosphere in the decades of the comparisons, there will be differences in the modelled and observed tides.

The fact that the differences for CMAM are small, or limited to a few features, indicates that CMAM includes the dominant physical, radiative and dynamical processes. Very focused GCM experiments will be needed to establish the atmospheric characteristic which is the cause of any particular difference between model and observation. Tides are the probably the most demanding of any dynamical feature to successfully model, but there is reason to believe that further modelling experiments can improve both tidal modelling and our understanding of atmospheric processes in general. There are further remarks in the Sect. 7.

\section{Planetary waves, annual height-time contour plots (16-, 2-d)}

\subsection{6-d planetary wave}

It was already shown, in the wavelets of Fig. 2 and discussion in Sect. 4, that the amplitudes for periods greater than 10-d at both 76 and $85 \mathrm{~km}$ were greater in the observed (MFR) than in the model (CMAM) data. The height (circa 60-90 km) versus time (months in 2001-2002 and in model years 3132) contours of Figs. 11 and 12 show this in more detail. In comparing model to observation we must be careful to consider only the general level of activity and not particular time-height "events", as the model is free-running and not a data-assimilation system.

In CMAM (Fig. 11, left side) we note large amplitudes $(\sim 13 \mathrm{~m} / \mathrm{s})$ as early as November and re-occurring in bursts until March-April. The amplitudes are large from 55-75 km in winter-centered months and then from near $75 \mathrm{~km}$ to the top of the summer's westward jet $(\sim 87 \mathrm{~km})$. There is evident contour-similarity at the three CUJO sites near $40^{\circ}$ (London, Platteville and Wakkanai). We show EW amplitudes, and these dominate over the NS (not shown), as expected for this normal (PW) mode. This pattern of pre-winter solstice activity was seen in the 8 other model years after year 31 that were assessed (32/33-40/41).

The observations (Fig. 11, right side) are significantly different: the winter amplitudes are largest later in the winter (January-March) for the three $40^{\circ}$ CUJO locations; the winter amplitudes remain large up to near $90 \mathrm{~km}$; there is significant longitudinal variability (e.g. Wakkanai and Platteville in March) as already noted by Luo et al. (2000, 2002a, b) and Manson et al. (2004c); and the summer contours (maxima near $80 \mathrm{~km}$ ) vary more in timing and heights than for CMAM. Luo et al. (2000) compared 10 years of such 16-d PW activity at Saskatoon, and found that 7 of 10 years had greater amplitudes later in winter; there was also significant variability in the size and placement of the summer maxima near the zonal wind reversal. Also note the observed maximum height of the summer's westward jet is lower $(\sim 80 \mathrm{~km})$ and more variable (see Wakkanai at $85 \mathrm{~km}$ ) than the modeled heights.

Comparing observations with model, we note that the MFR 16-d PW amplitudes are comparable or larger than CMAM at comparable heights, even without allowing for the MFR bias toward smaller values. There may be differences in the damping of these normal (resonant) modes, with height, between the real and modeled atmospheres. Mechanisms in CMAM include radiative damping and eddy diffusion. The real atmosphere may also be offering modest barotropic or baroclinic instability at the $75-90 \mathrm{~km} \mathrm{lev-}$ els (Andrews et al., 1987) which would enhance the observed waves. There could also be less geophysical forcing of these modes in the early winter of the real atmosphere. Meyer and Forbes (1997), using the 2-D Global Scale Wave Model (GSWM), showed that longer period PW ( $>10 \mathrm{~d})$ are strongly damped above $90 \mathrm{~km}$, due to Newtonian cooling, molecular viscosity and ion-drag (the latter being dominant).

Another possibility for the larger mesospheric PW amplitudes (or activity) in CMAM in early winter (November, December) could be the strength of the modeled winter vortex. From Charney and Drazin (1961) and Manson et al. (2005), weaker eastward flow (u) leads to smaller intrinsic phase velocities (u-c) for the 16-d PW (westward propagating), a decreased chance of this (u-c) exceeding the "limiting speed" (this later is inversely proportional to the squared wave-numbers) and a resulting larger amplitude for vertically propagating waves. In fact, the CMAM zonal winds at $55 \mathrm{~km}$ (Fig. 11, and the 8 other model years) in November/December are $20-30 \mathrm{~m} / \mathrm{s}$ weaker than those in CIRA (1986). These are heights where CIRA is at its most reliable. Thus PW propagation into the mesosphere is favored within CMAM during the early months of the winter-season's eastward flow. The mean winds (CIRA) are more similar to CMAM in January/February when the PW amplitudes (or wave activity) from CMAM and the MFRs at $70 \mathrm{~km}$ are more similar (Figs. 11 and 12). This factor may well explain the discrepancy between modeled and observed PW activity in the mesosphere early in the winter months.

\subsection{2-d planetary wave}

The initial step was to assess the CMAM winds spectra near periods of two days, to confirm the presence of the so-called Quasi 2 Day Wave (Q2DW) in these data. Monthly spectra for the 21 years of data clearly showed strong features centred on 2-d for the summer months. The spectral filter described in Sect. 2.4 (1.5-3 days), which covers the normal spectral variability of the Q2DW (Manson et al., 2004c), was therefore used for the plots described below. 

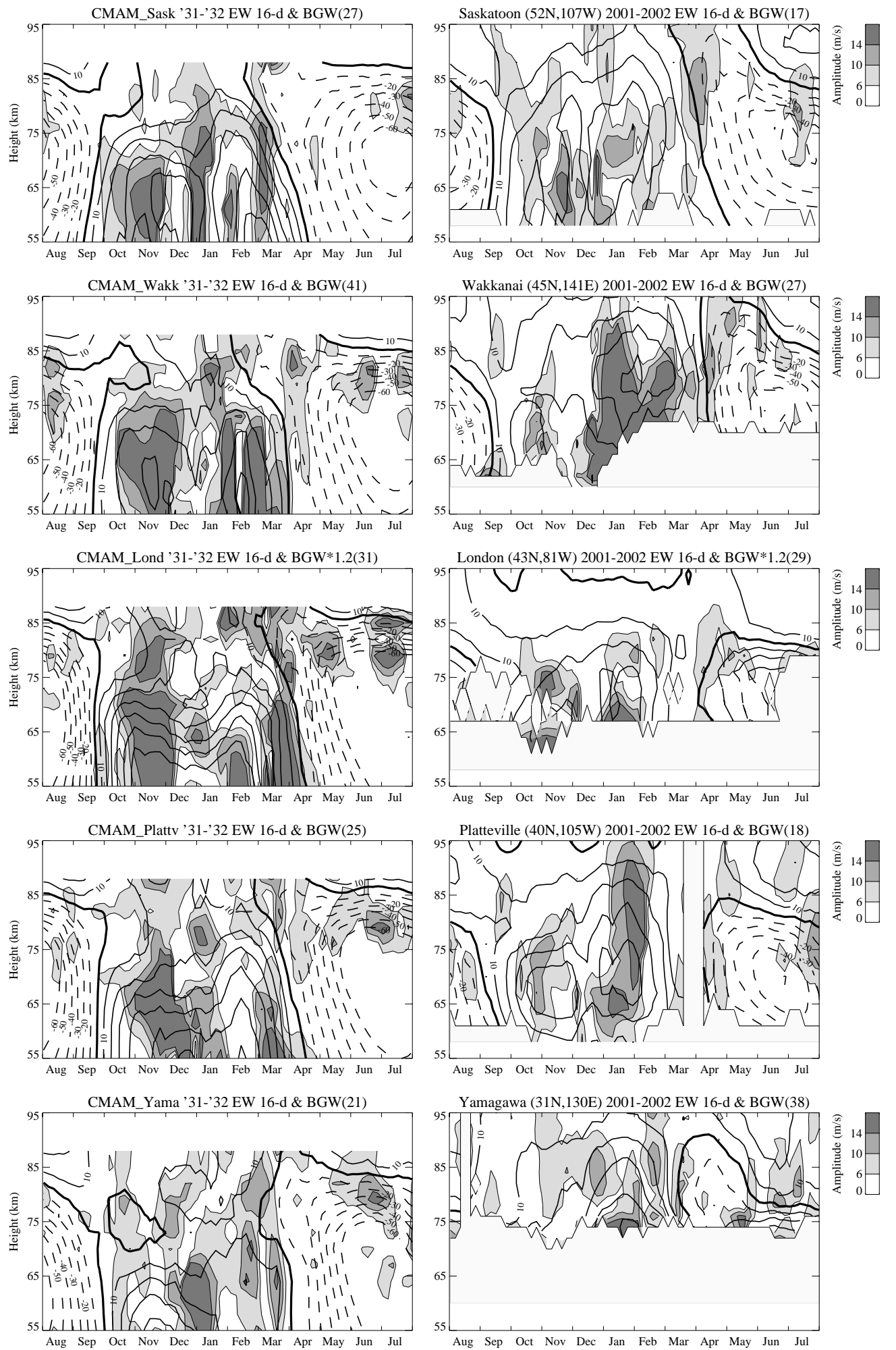

Fig. 11. Amplitudes of the 16-d planetary wave (NS and EW) resulting from a Fourier analysis (bandwidth 13-19 days; 48-day window length shifted in 5-day steps over the year) of CMAM data (model-years 31/32) and of MF radar data (years 2001/02). For each windowlength the mean (48-day) is removed and used to represent the background wind: continuous lines for eastwards winds, dashed lines for the westward. The locations are Saskatoon, Wakkanai, London and Platteville. Data amplitudes from London's MFR are multiplied by a factor of 1.2 due to a bias in the local analysis. The number in brackets at the top of each panel gives the maximum value found in those data. 

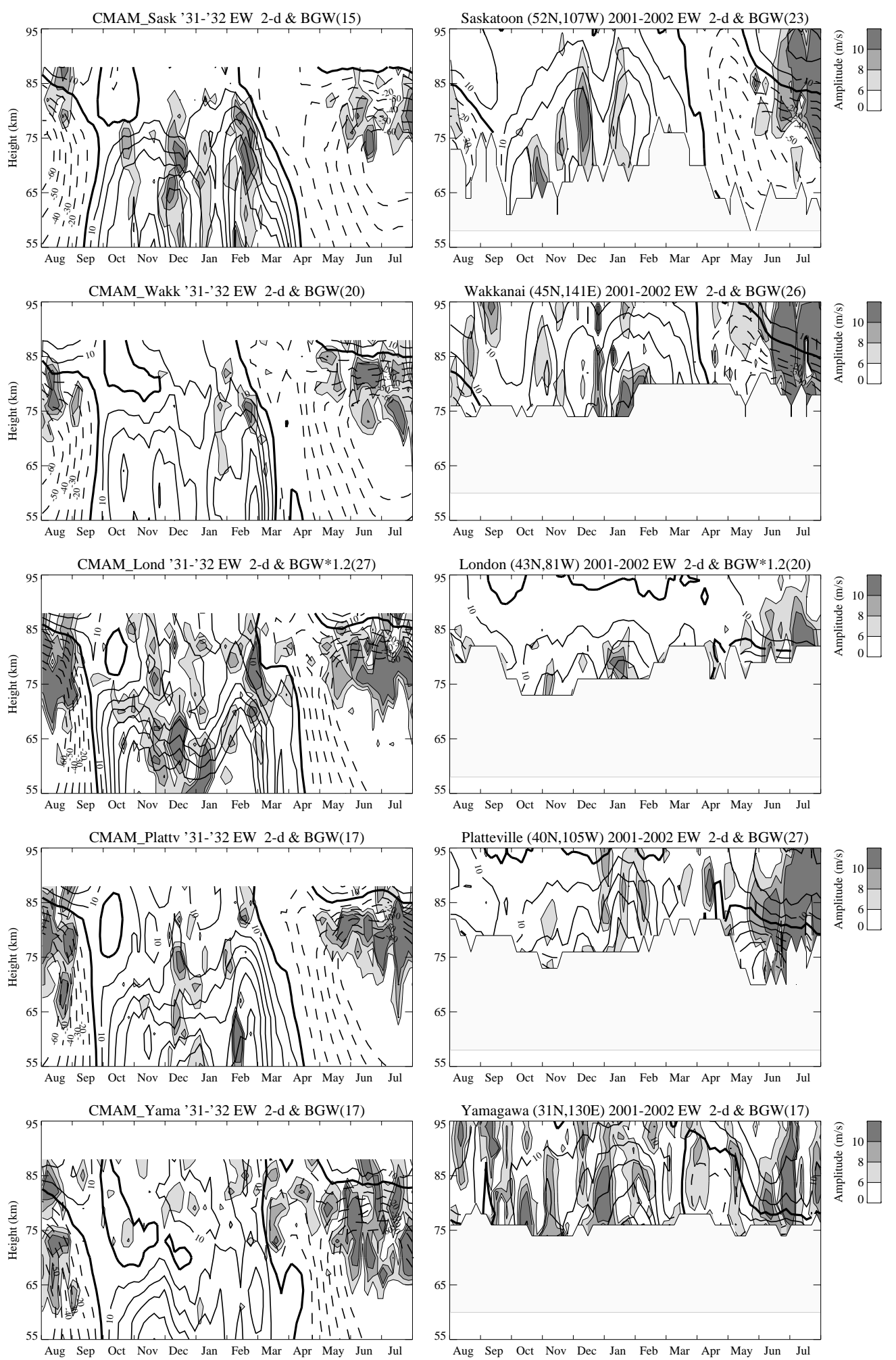

Fig. 12. Amplitudes of the 2-d planetary wave (NS and EW) resulting from a fourier analysis (bandwidth 1.5-3 days; 24-day window length shifted in 5-day steps over the year) of CMAM data (model-years 31/32) and of MF radar data (years 2001/02). For each window-length the mean (24-days) is removed and used to represent the background wind: continuous lines for eastwards winds, dashed lines for the westward. The locations are Saskatoon, Wakkanai, London and Platteville. Data amplitudes from London's MFR are multiplied by a factor of 1.2 due to a bias in the local analysis. The number in brackets at the top of each panel gives the maximum value found in those data. 
In the CMAM annual contour-plots (left side of Fig. 12, model years 31-32) we note dominant summer activity (midMay to early September) in the mesopause region reaching up to the zero transition line near $87 \mathrm{~km}$. Amplitudes reach the $\sim 10 \mathrm{~m} / \mathrm{s}$ contour level and seldom exceed $10 \mathrm{~m} / \mathrm{s}$. There are indications of weaker (seldom reaching $10 \mathrm{~m} / \mathrm{s}$ ) and intermittent winter activity at lower heights $(60-80 \mathrm{~km})$. This latter has only recently received attention in the literature (Manson et al., 2004a, c). The NS and EW components are of comparable strength and occurrence, with the EW (shown here) being modestly larger. Five additional years were analyzed and were all consistent with the above.

The observed annual contour plots are significantly different (right side of Fig. 12). The summer amplitudes are larger (the plots are filled with values beyond $10 \mathrm{~m} / \mathrm{s}$ values) with maxima commonly in the $15-25 \mathrm{~m} / \mathrm{s}$ range. Also, although the activity extends from May to August, it strongly peaks in June and July. This is clear in a 14 year compilation for Saskatoon also (Chshyolkova et al., 2005). The wave activity in Fig. 12 (and the compilation) extends to $95 \mathrm{~km}$ (even with the increasing bias toward smaller values from the MFR systems: Sect. 2) and maximizes near $85 \mathrm{~km}$, while in CMAM the amplitudes decrease toward $87 \mathrm{~km}$ and maximize near $80 \mathrm{~km}$. This height difference is similar to that of the 16$\mathrm{d}$ wave, and could be associated with the "sponge layer" in CMAM above $80 \mathrm{~km}$.

The observed winter activity (2001-2002) is also different from that modeled. Although it also maximizes at the lower heights $(\sim 75 \mathrm{~km})$ it frequently reaches up to $90-95 \mathrm{~km}$ (Fig. 12). The 14 year compilation for Saskatoon (Chshyolkova et al., 2005) shows this very clearly. The winteramplitudes frequently reach and exceed $10 \mathrm{~m} / \mathrm{s}$ in our figure (EW), and NS components (not shown) are comparable for the range of latitudes in the figure. It is worthy of note that the MFR amplitudes for Q2DW activity are larger than modeled, in both seasons, even without allowing for the MFR bias toward smaller values (factors of $10 \%(85 \mathrm{~km})$ $60 \%(97 \mathrm{~km})$, Sect. 2.1).

There are many substantial studies of this Rossby-gravity wave (Q2DW) in the literature, where the sources and forcing of the oscillation are studied in great detail. We mention several: Salby (1981) provided the first quantitative treatment, and demonstrated that propagation of the 2-d wave $(\mathrm{m}=3)$ was favoured by a mean flow that was modestly eastward of this westward propagating wave. This work was significantly developed by Hagan et al. (1993) who used their 2-D GSWM in the January summer (SH) solstice, and with three global mean wind fields, to investigate the 2-d PW ( $\mathrm{m}=3$ mode) propagation behaviour. Consistent with the discussion of refractive index in Manson et al. (2005), which is based on Charney and Drazin (1961), the wave may be expected to reach the summer mesopause (Hagan et al., 1993).

In winter the eastward mean flow of the middle atmosphere leads to larger intrinsic phase speeds, so the "limiting speed", which is an inverse-function of wave number $(\mathrm{m}=3)$, is relatively small for the 2 - $\mathrm{d}$ wave and rather easily exceeded during the winter months. Hence, as Hagan et al. (1993) demonstrate, the amplitudes are smaller than in summer. Their variability (Figs. 11, 12) is consistent with variability of the winter-vortex.

Instability processes have also been included in the assessment of the Q2DW. The interaction of that normal mode with the "generally unstable mean (zonal) flow" (Salby and Callaghan, 2001, 2003) provides oscillations of similar period (2.0-2.2 days) and with likely wave numbers of 3 and 4. Planetary waves (longer period) can also provide transient forcing in winter months. Finally, Riggin et al. (2004) studied the Q2DW at high latitudes during the boreal summer (1994), and concluded that in-situ excitation at high latitudes was the cause of the wave in the mesosphere (wave number two).

We do not intend to proceed further, at this time, with a detailed study of the Q2DW in either CMAM or by using the MFR data. Model-data from a more global experiment would be required in the former case; similarly, a better longitudinal array of radars is required to determine wave-numbers along with a suite of complementary satellite measurements. 2001/2002 is not an ideal interval of time for the latter. Our appropriate summary at this stage is that typical annual contour plots and climatologies of the Q2DW from CMAM and MFR data reveal quite similar behaviour. The main differences are similar to those noted for the 16-d PW, with modeled amplitudes being smaller, and the waves extending less deeply into the MLT region. While the friction sponge within CMAM could be partly responsible, the reduced amplitudes are also evident below $80 \mathrm{~km}$. Forcing of the PW and or filtering by the stratospheric winds have been suggested as possible explanations.

\subsection{Discussion of the modelled planetary waves in CMAM}

Causes for differences between modelled and observed PW have been discussed already within Sects. 3 and 6. To summarize: planetary and gravity waves both modify the hemispheric middle atmosphere wind systems and the meridional temperature gradients; these winds in turn modify the propagation and hence climatologies of both types of wave; and PW frequently originate in the troposphere associated with orographic forcings, instabilities or as resonant structures responding to geophysical noise in the system. While there are useful agreements between observed PW activity and those modelled in CMAM, there are also indications in this present study that PW activity at high latitudes (associated with SSW) and at middle latitudes (altitudinal and seasonal variations) depart consistently from observations.

Again, as with tides, well designed and comprehensive experiments, complete with adequate diagnostics, would be required to resolve the main causes of these discrepancies. Data assimilation, as now is proceeding, is likely to resolve 
some of these remaining dynamical issues within GCMs in general and CMAM in particular.

\section{Summary and comments}

Given the extensive discussion within the Sections, only a brief summary of the findings is included here along with a discussion of the questions that are raised.

Following earlier comparisons using CMAM (without chemistry) by Manson et al. (2002a, b), the dynamical characteristics of the model are assessed with interactive chemistry (de Grandpré et al., 2000). Time sequences of temperatures and winds at Troms $\varnothing(70 \mathrm{~N})$ show that the model has more frequent and earlier warmings, confirming an earlier study. Wavelets at one MetO and two MLT heights (50, 76, $85 \mathrm{~km}$ ) show CMAM tides are often larger, but PW smaller, than MF radar-derived values. High-resolution spectra, show that the tidal features within CMAM are often "noisy", which may indicate GW-tidal interactions.

Tides from the CMAM with interactive chemistry are not strikingly different from the first CMAM experiments (Manson et al., 2002a, b; Papers 1 \& 2). However, the monthly data allow annual "height versus time" plots for the tides observed/modelled at specific locations (combinations of migrating and non-migrating components) to be produced for the first time, and this enables more detailed comparisons of tidal features to be made. The dominant semi diurnal tide of middle latitudes is, as in earlier papers, well realized in CMAM; there are winter maxima, and notably for a model, the large maximum in late summer-fall. At mid-latitudes, both CMAM and MFR provide medium (circa $50 \mathrm{~km}$ ) vertical wavelengths in winter and long values in summer above 60 and $80 \mathrm{~km}$, respectively. However, the observed wavelengths are much smaller $(30 \mathrm{~km})$ at heights below $80 \mathrm{~km}$, indicating the influence of other tidal modes.

Consistent with McLandress (2002a, b), the main characteristics of the diurnal tide at low latitudes (where the $\mathrm{S}(1,1)$ mode dominates) are well captured by the model. There remain some issues however: the modelled low latitude equinoctial amplitudes (at $82 \mathrm{~km}$ ) are larger than observed (even when allowance is made for the expected MFR data's low-speed bias), and middle latitudes feature an unobserved low altitude $(73 \mathrm{~km})$ summer maximum. Phases, especially at low-middle latitudes $\left(<52^{\circ} \mathrm{N}\right)$ do not match observations very well: while CMAM implies the dominance of $S(1,1)$ and $S(1,-1)$ at Hawaii and Saskatoon, respectively, the observed tides are more modally-mixed in character. This latter is related to the modelled NS temperature gradients, background winds, effective eddy diffusion values and non migrating tides.

Climatologies from the " $40^{\circ} \mathrm{N}$ " CUJO network reveal interesting similarities and differences between the winds and waves from CMAM and MFR data sets. There are evident longitudinal variations in tides within both data sets, consis- tent with non-migrating tides (NMT). However, the variations in CMAM tides are smaller than those observed, while those in the MFR tides are more consistent with NMT analysis applied to UARS-HRDI data. The percentage of the tidal power in the migrating tides show maxima in the diurnal tide during equinox, and for the semi diurnal tide during the fall maximum, for both CMAM and MFR data. The standard deviations of the CMAM tides (21 years) and MFR (14 years), shown in climatological contour form, affirm the moderate inter-annual variability of both data sets; however differences that do exist highlight systematic differences in the two climatologies.

As noted in Sect. 5.5, such modelled/observational differences for the tides, associated with any generic GCM, can be due to several factors: forcing by heating processes involving ozone and water (including phase-changes); dissipation of the tides; propagation of the tides through the wind and temperature fields of the middle atmosphere; and different combinations of non-migrating tides. All of these require assessment in any detailed diagnostic study of modelled tides. However, given that the differences from observations indicated by this experiment with CMAM are relatively small, or limited to a few features, it suggests that CMAM includes the dominant physical, radiative and dynamical processes of the atmosphere.

Finally, the PW height versus time plots from CMAM and MFR data sets show useful agreement, apart from the amplitude differences (smaller in CMAM above $70 \mathrm{~km}$ ). A major difference for the 16-d PW is that CMAM shows large amplitudes before the winter solstice, which is thought to be due to the weaker stratospheric vortex; and for the 2-d PW, while both CMAM and MFR show summer and winter activity, the observed summer mesopause and winter mesospheric activities are stronger and more extended spatially. Such differences, in any generic GCM, can be due to both PW forcing in the model and propagation of the PW through the modelled winds of the middle atmosphere. As noted in Sect. 6.3, the PW themselves have a strong role in establishing those winds (and the related meridional temperature gradients).

We conclude with some comments concerning desirable directions for subsequent studies. These statements are generic rather than specific to the model used here (CMAM). Full diagnosis of the reasons for tidal differences between observations and models will require more extensive experiments than that carried out here. In this context, it is worthy of general comment, that such experiments require significant effort and resources, which are not always considered when modelling collaborations are proposed. Part of such extended studies should involve assessment of middle atmospheric distributions of ozone and water vapour, and then calculations of the Hough modes that are being forced, as a function of season. Other topics for tidal studies should include the wind and temperature fields of the model, and the causes for any deficiencies in these. Further studies of the NMT tides are also required in models extending not only 
to the mesopause region (circa $85 \mathrm{~km}$ ), but also higher into the thermosphere. Ward et al. (2005) have published results on the NMT from the extended CMAM version. The NMT compare well in terms of amplitude with existing observations e.g. HRDI-UARS, although a phase error renders the wave-number 2 features in their Fig. 2 incorrect (W. Ward, private communication) and a correction is in process. It is expected that studies of the NMT will be carried out during the campaigns associated with projects of CAWSES (Climate and Weather of the Sun Earth System), 2004-2008.

Diagnostic studies are also required to understand why the SSW (sudden stratospheric warmings) is not well reproduced in some models, and a related matter, why the characteristics of modelled planetary waves (PW) may lack some observed features. It is also increasingly apparent that successful modelling of the equatorial semi-annual oscillation and the QBO (e.g. Pascoe et al., 2006) are important for improved characterization of global wind, temperature and PW fields at extratropical latitudes. Such studies would be extremely valuable, as these issues indicate that modelled PW-GW-polar vortex characteristics and wave-interactions are not in fully realistic balance in some models. There also remain issues regarding the parameterization of GW. These waves have a dominant role in closing the polar vortices, but we need to know whether different parameterization schemes have different effectiveness in driving the tides, or perhaps modifying their phases and periods.

Finally and specifically with regard to CMAM, dataassimilation involving data from troposphere-middle atmosphere is now underway. Experiments similar to the above, using this model, will be carried out in 2007/08. Results from this will also be valuable for the SCOSTEP-CAWSES project "Atmospheric Wave Interactions with the Winter Polar Vortices $(0-100 \mathrm{~km})$ ". Colleagues, who wish to engage in related collaborative activity with CMAM on any of the issues discussed above, would be welcomed by the authors of this paper.

Acknowledgements. Authors A. H. Manson, C. Meek, T. Chshyolkova mention with thanks the support of the "Natural Sciences and Engineering Research Council" (NSERC) Granting Agency, and the University of Saskatchewan through ISAS; C. McLandress thanks the "Global Chemistry for Climate" Project (NSERC) and the Canadian Space Agency for support. The other authors wish to acknowledge the support of grants from their National Agencies.

Topical Editor U.-P. Hoppe thanks one referee for her/his help in evaluating this paper.

\section{References}

Andrews, D. G., Holton, J. R., and Leovy, C. B.: Middle Atmosphere Dynamics, Academic Press, p 489, 1987.

Baldwin, M., Hirooka, T., O’Neill, A., and Yoden, S.: Major stratospheric warming in the Southern Hemisphere in 2002: Dynamical aspects of the ozone hole split, SPARC Newsletter, 20, 24-26, 2003.
Beagley, S. R., de Grandpré, J., Koshyk, J. N., McFarlane, N. A., and Shepherd, T. G.: Radiative dynamical climatology of the first generation Canadian middle atmosphere model, Atmos. Ocean, 35, 293-331, 1997.

Chaffey, J. D. and Fyfe, J. C.: Arctic Polar Vortex Variability in the Canadian Middle Atmosphere Model, Atmos. Ocean, 39, 457 469, 2001

Charney, J. G. and Drazin, P. G.: Propagation of planetary-scale disturbances from lower into the upper atmosphere, J. Geophys. Res., 66, 83-109, 1961.

Chshyolkova, T., Manson, A. H., and Meek, C. E.: Climatology of the quasi two-day wave over Saskatoon $\left(52^{\circ} \mathrm{N}, 107^{\circ} \mathrm{W}\right): 14$ Years of MF radar observations, Adv. Space Res., 35, $2011-$ 2016, 2005.

Chshyolkova, T., Manson, A. H., Meek, C. E., Avery, S. K., Thorsen, D., MacDougall, J. W., Hocking, W., Murayama, Y., and Igarashi, K.: Planetary wave coupling processes in the middle atmosphere $(30-90 \mathrm{~km})$ : a study involving MetO and MF radar data, J. Atmos. Solar-Terr. Phys., 68, 353-368, 2006.

de Grandpré, J., Beagley, S. R., Fomichev, V. I., Griffioen, E., McConnell, J. C., Medvedev, A. S., and Shepherd, T. G.: Ozone climatology using interactive chemistry: Results from the Canadian Middle Atmosphere Model, J. Geophys. Res., 105(D21), 26475-26 491, 2000.

de Grandpré, J., Sandilands, J. W., McConnell, J. C., Beagley, S. R., Croteau, P. C., and Danilin, M. Y.: Canadian Middle Atmosphere Model: Preliminary results from the Chemical Transport Module, Atmos. Ocean, 35, 385-431, 1997.

Hagan, M. E.: Comparative effects of migrating solar sources on tidal signatures in the middle and upper atmosphere, J. Geophys. Res., 101, 21 213-21 222, 1996.

Hagan, M. E., Forbes, J. M., and Vial, F.: Numerical Investigation of the Propagation of the Quasi 2-Day Wave into the Lower Thermosphere, J. Geophys. Res., 98, 23 193-23 205, 1993.

Hines, C. O.: Doppler-spread parameterization of gravity wave momentum deposition in the middle atmosphere Part I: Basic formulation, J. Atmos. Solar-Terr. Phys., 59, 371-386, 1997a.

Hines, C. O.: Doppler-spread parameterization of gravity wave momentum deposition in the middle atmosphere Part II: Broad and quasi monochromatic spectra and implementation, J. Atmos. Solar-Terr. Phys., 59, 387-400, 1997b.

Isler, J. R. and Fritts, D. C.: Gravity wave variability and interaction with lower-frequency motions in the mesopause and lower thermosphere over Hawaii, J. Atmos. Sci., 53, 37-48, 1996.

Keating, G. M., Pitts, M. C., and Young, D. F.: Ozone reference models for the middle atmosphere, Adv. Space Res., 10(12), $12317-12355,1990$.

Kumar, P. and Foufoula-Georgiou, E.: Wavelet analysis for geophysical applications, Rev. Geophys., 35(4), 385-412, 1997.

Liu, H.-L. and Roble, R. G.: A study of a self-generated stratospheric sudden warming and its mesospheric-lower thermospheric impacts sing the coupled TIME-GCM/CCM3, J. Geophys. Res., 107(D23), 4695, doi:10.1029/2001JD001533, 2002.

Luo, Y., Manson, A. H., Meek, C. E., Meyer, C. K. Burrage, M. D., Fritts, D. C, Hall, C. M., Hocking, W. K., MacDougall, J., Riggin, D. M., and Vincent, R. A.: The 16-day planetary waves: multi-MF radar observations from the arctic to equator and comparisons with the HRDI measurements and the GSWM modelling results, Ann. Geophys., 20, 691-709, 2002a. 
Luo, Y., Manson, A. H., Meek, C. E., Thayaparan, T., MacDougall, J., and Hocking, W. K.: The 16-day wave in the mesosphere and lower thermosphere: simultaneous observations at Saskatoon $\left(52^{\circ} \mathrm{N}, 107^{\circ} \mathrm{W}\right)$ and London $\left(43^{\circ} \mathrm{N}, 81^{\circ} \mathrm{W}\right)$, Canada, J. Atmos. Solar-Terr. Phys., 64, 1287-1307, $2002 \mathrm{~b}$.

Luo, Y., Manson, A. H., Meek, C. E., Meyer, C. K., and Forbes, J. M.: The quasi 16-day oscillations in the mesosphere and lower thermosphere at Saskatoon (52 N, 107 W), 1980-1996, J. Geophys. Res., 105, 2125-2138, 2000.

Manson, A. H., Meek, C. E., Chshyolkova, T., Avery, S. K., Thorsen, D., MacDougall, J. W., Hocking, W., Murayama, Y., and Igarashi, K.: Wave Activity (planetary, tidal) throughout the middle atmosphere $(20-100 \mathrm{~km})$ over the CUJO network: Satellite (TOMS) and Medium Frequency (MF) radar observations, Ann. Geophys., 23(2), 305-323, 2005.

Manson, A. H., Meek, C. E., Hall, C. M., Nozawa, S., Mitchell, N. J., Pancheva, D., Singer, W., and Hoffmann, P.: Mesopause dynamics from the Scandinavian triangle of radars within the PSMOS-DATAR Project, Ann. Geophys., 22, 367-386, 2004a.

Manson, A. H., Meek, C. E., Hagan, M., Zhang, X., and Luo, Y.: Global distributions of diurnal and Semi-diurnal tides: Observations from HRDI-UARS of the MLT region and comparisons with GSWM-02 (migrating, non-migrating components), Ann. Geophys., 1529-1548, 2004b.

Manson, A. H., Meek, C. E., Avery, S. K., Thorsen, D., Hocking, W. K., MacDougall, J. W., Igarashi, K., Namboothiri, S. P., and Murayama, Y.: Longitudinal and Latitudinal Variations in Dynamic Characteristics of the MLT (70-95 km): A study involving the CUJO network, Ann. Geophys., 347-365, 2004c.

Manson, A. H., Meek, C. E., Avery, S. D., and Thorsen, D.: Ionospheric and dynamical characteristics of the MLT region over Platteville $(40 \mathrm{~N}, 105 \mathrm{~W})$ and comparisons with the region over Saskatoon (52 N, 107 W), J. Geophys. Res., 108(D13), 4398, doi:10.1029/2002JD002835, 2003.

Manson, A. H., Meek, C. E., Koshyk, J., Franke, S., Fritts, D. C., Riggin, D., Hall, C. M., Hocking, W. K., MacDougall, J., Igarashi, K., and Vincent, R. A.: Gravity wave activity and dynamical effects in the middle atmosphere $(60-90 \mathrm{~km})$ : observations from an MF/MLT Radar Network, and results from the Canadian Middle Atmosphere Model (CMAM), J. Atmos. SolarTerr. Phys, 64, 65-90, 2002a.

Manson, A. H., Meek, C. E., Hagan, M., Koshyk, J., Franke, S., Fritts, D., Hall, C., Hocking, W., Igarashi, K., MacDougall, J., Riggin, D., and Vincent, R.: Seasonal variations of the semidiurnal and diurnal tides in the MLT: multi-year MF radar observations from $2-70^{\circ} \mathrm{N}$, modeled tides (GSWM, CMAM), Ann. Geophys., 20, 661-667, 2002b.

Manson, A. H, Luo, Y., and Meek, C. E.: Global Distributions of Diurnal and Semi- Diurnal Tides: Observations from HRDIUARS of the MLT Region, Ann. Geophys., 20, 1877-1890, 2002c.

Manson, A. H., Meek, C. E., Stegman, J., Espy, P. J, Roble, R. G., Hall, C. M., Hoffmann, P., and Jacobi, Ch.: Springtime transitions in mesopause airglow and dynamics: photometer and MF radar observations in the Scandinavian and Canadian sectors, J. Atmos. Solar-Terr. Phys., 64, 1131-1146, 2002d.

Manson, A. H., Meek, C. E., Hagan, M., Hall, C., Hocking, W., MacDougall, J., Franke, S., Riggin, D., Fritts, D., Vincent, R., and Burrage, M.: Seasonal variations of the semi-diurnal and diurnal tides in the MLT: multi-year MF radar observations from 2 to $70^{\circ} \mathrm{N}$, and the GSWM tidal model, J. Atmos. Solar-Terr. Phys., 61, 809-828, 1999.

Manson, A. H., Yi, F., Hall, G., and Meek, C. E.: Comparisons between instantaneous wind measurements made at Saskatoon $(52 \mathrm{~N}, 107 \mathrm{~W})$ using the co-located medium frequency radars and Fabry-Perot interferometer instruments climatologies (1988-1992) and case studies, J. Geophys. Res., 101, 2955320563, 1996.

Manson, A. H. and Meek, C. E.: Winds and Tidal Oscillations in the Upper Middle Atmosphere at Saskatoon $\left(52^{\circ} \mathrm{N}, 107^{\circ} \mathrm{W}, \mathrm{L}=4.3\right)$ During the Year June 1982-May 1983, Planet. Space Sci., 32, 1087-1099, 1984.

Manson, A. H., Meek, C. E., Gregory, J. B., and Chakrabarty, D. K.: Fluctuations in Tidal (24-, 12-h) Characteristics and Oscillations (8-h-5-d) in the Mesosphere and Lower Thermosphere (70-110 km); Saskatoon $\left(52^{\circ} \mathrm{N}, 107^{\circ} \mathrm{W}\right)$ 1979-1981, Planet. Space Sci., 30, 1283-1294, 1982.

McFarlane, N. A.: The effect of orographically excited gravity wave drag on the general circulation of the lower stratosphere and troposphere., J. Atmos. Sci., 44, 1775-1800, 1987.

McLandress, C.: The seasonal variation of the propagating diurnal tide in the mesosphere and lower thermosphere. Part I: The roles of gravity waves and planetary waves, J. Atmos. Sci., 59(5), 893906, 2002a.

McLandress, C.: The seasonal variation of the propagating diurnal tide in the mesosphere and lower thermosphere. Part II: the roles of tidal heating and zonal mean winds, J. Atmos. Sci., 59(5), 907-922, 2002b.

McLandress, C.: On the importance of gravity waves in the middle atmosphere and their parameterization in general circulation models, J. Atmos. Solar-Terr. Phys., 60, 1357-1384, 1998.

Medvedev, A. S. and Klaassen, G. P.: Vertical evolution of gravity wave spectra and the parameterization of associated wave drag, J. Geophys. Res., 100, 25 841-25 853, 1995.

Meek, C. E.: An efficient method for analyzing ionospheric drifts data, J. Atmos. Terr. Phys., 42, 835-839, 1980.

Meek, C. E., Manson, A. H., Burrage, M. D., Garbe, G., and Cogger, L. L.: Comparisons between Canadian Prairie MF Radars, FPI (green and OH Lines) and UARS HRDI Systems, Ann. Geophys., 15, 1099-1110, 1997, http://www.ann-geophys.net/15/1099/1997/.

Meyer, C. K. and Forbes, J. M.: Natural oscillations of the ionosphere-thermosphere-mesosphere (ITM) system, J. Atmos. Solar-Terr. Phys., 59, 2185-2202, 1997.

Naujokat, B., Krüger, K., Matthes, K., Hoffmann, J., Kunze, M., and Labitzke, K.: The early major warming in December 2001 - exceptional? Geophys. Res. Lett., 29(21), 2023, doi:10.1029/2002GL015316, 2002.

Orsolini, Y. J., Limpasuvan, V., and Leovy, C.: The tropical stratopause in the UKMO stratospheric analyses: Evidence for a 2-day wave and inertial circulations, Quart. J. Roy. Meteorol. Soc., 123, 1707-1724, 1997.

Pascoe, C. L., Gray L. J., and Scaife, A. A.: A GCM study of the influence of equatorial winds on the timing of sudden stratospheric warmings, Geophys. Res. Lett., 33, L06825, doi:10.1029/2005GL024715, 2006.

Randel, W. J.: Global Variations of Zonal Mean Ozone during Stratospheric Warming Events, J. Atmos. Sci., 50(19), 3308, 
1993.

Riggin, D. M., Lieberman, R. S., Vincent, R. A., Manson, A. H., Meek, C. E., Nakamura, T., Tsuda, T., and Portnyagin, Y. I.: The 2-day wave during the boreal summer of 1994, J. Geophys. Res., 109, D08110, doi:10.1029/2003JD004493, 2004.

Riggin, D. M., Meyer, C. K., Fritts, D. C., Jarvis, M. J., Murayama, Y., Singer, W., Vincent, R. A., and Murphy, D. J.: MF radar observations of seasonal variability of semidiurnal motions in the mesosphere at high northern and southern latitudes, J. Atmos. Solar-Terr. Phys., 65(4), 483-493, 2003.

Salby, M. L. and Callaghan, P. F.: Dynamics of the 2-day wave in a nonlinear model of the middle and upper atmosphere, J. Geophys. Res., 108(D23), 4713, doi:10.1029/2003JD003648, 2003.

Salby, M. L. and Callaghan, P. F.: Seasonal amplification of the 2day wave: relationship between normal mode and instability, J. Atmos. Sci., 58, 1858-1869, 2001.

Salby, M. L.: Rossby Normal Modes in Non-uniform Background Configurations. Part II: Equinox and Solstice Conditions, J. Atmos. Sci., 38, 1827-1840, 1981.

Shepherd, T. G.: The middle atmosphere, J. Atmos. Solar-Terr. Phys., 62, 1587-1601, 2000.

Swinbank, R. and O'Neill, A.: A stratosphere-troposphere data assimilation system, Mon. Wea. Rev., 122, 686-702, 1994a.

Swinbank, R. and O'Neill, A.: Quasi-biennial and semi-annual oscillations in equatorial wind fields constructed by data assimilation, Geophys. Res. Lett., 21, 2099-2102, 1994b.
Swinbank, R. and Ortland, D. A.: Compilation of wind data for the Upper Atmosphere Research Satellite (UARS) Reference Atmosphere Project, J. Geophys. Res., 108(D19), 4615, doi:1029/2002JD003135, 2003.

Vial, F. and Forbes, J. M.: Recent progress in tidal modelling, J. Atmos. Solar-Terr. Phys., 51, 663-671, 1989.

Vincent, R. A., Kovalam, S., Fritts, D. C., and Isler, J. R.: Longterm MT radar observations of solar tides in the lo-latitudes mesosphere: Interannual variability and comparisons with the GSWM, J. Geophys. Res., 103, 8667-8683, 1998.

Walterscheid, R. L.: Inertio-Gravity Wave-Induced Accelerations of Mean Flow having an Imposed Periodic ComponentImplications for Tidal Observations in the Meteor Region, J. Geophys. Res.-Oceans and Atmospheres, 86(NC10), 96989706, 1981.

Ward, W. E., Fomichev, V. I., and Beagley, S.: Non-migrating tides in equinox temperature fields from the Extended Canadian Middle Atmosphere Model (CMAM), Geophys. Res. Lett., 32, L03803 doi:10.1029/2004GL021466, 2005.

Zhan, Q., Manson, A. H., and Meek, C. E.: The impact of gaps and spectral methods on the spectral slope of the middle atmospheric wind, J. Atmos. Solar-Terr. Phys., 58, 1329-1336, 1996.

Zhang, G. J. and McFarlane, N. A.: Sensitivity of climate simulations to the parameterization of cumulus convection in the CCC GCM, Atmos. Ocean, 33, 407-446, 1995. 